\title{
Linear polyurethanes with imidazoquinazoline rings: preparation and properties evaluation
}

\author{
Agnieszka Szyszkowska ${ }^{1}$ Anna Czerniecka-Kubicka ${ }^{2,3} \cdot$ Marek Pyda $^{1}$. \\ Łukasz Byczyński $\cdot$ Kamil Gancarczyk $^{5} \cdot$ Vladimir Sedlarik $^{6} \cdot$ Iwona Zarzyka $^{1}[$
}

Received: 20 August 2018 / Revised: 19 December 2018 / Accepted: 7 February 2019 /

Published online: 20 February 2019

(c) The Author(s) 2019

\begin{abstract}
In this work, research concerning the synthesis and properties of linear polyurethanes (PUs) with the imidazoquinazoline rings was represented. Reaction conditions of 2,6-bis(2-hydroxyethyl)-1-phenylimida-zo[1,5-c]quinazoline-3,5-dione (BHPIQ) with 1,6-hexamethylene diisocyanate were determined and optimized. These conditions are adapted to reaction of BHPIQ with 4,4'-diphenylmethane diisocyanate and 2,4-toluene diisocyanate. New PUs with imidazoquinazoline rings were characterized by spectral methods ( ${ }^{1} \mathrm{H}-\mathrm{NMR}$ and IR spectroscopies), which confirm their structures. Their molar masses and dispersity index were measured by size exclusion chromatography method. The wide-angle X-ray scattering and differential scanning calorimetry (DSC) studies have shown that all PUs based on BHPIQ are amorphous. Moreover, thermal properties of PUs were investigated by thermogravimetry analysis, standard DSC, and temperature-modulated DSC methods. During thermogravimetric measurements, the exhaust gases were analyzed by FTIR method. Incorporation of imidazoquinazoline ring into the PU chains escalates their glass transition temperature; thus, their heat resistance was enhanced. Furthermore, their degradation rate and the amount of released degradation products were
\end{abstract}

Iwona Zarzyka

izarzyka@prz.edu.pl

1 Department of Organic Chemistry, Faculty of Chemistry, Rzeszów University of Technology, Powstańców Warszawy 6, 35-959 Rzeszow, Poland

2 Department of Experimental and Clinical Pharmacology, Faculty of Medicine, The University of Rzeszow, mjr. W. Kopisto 2 a, 35-310 Rzeszow, Poland

3 Department of Plastic Processing, Faculty of Mechanical Engineering and Aeronautics, Rzeszow University of Technology, Powstancow Warszawy 6, 35-959 Rzeszow, Poland

4 Department of Polymers and Biopolymers, Faculty of Chemistry, Rzeszów University of Technology, Powstańców Warszawy 6, 35-959 Rzeszow, Poland

5 Department of Material Science, Faculty of Mechanical Engineering and Aeronautics, Rzeszów University of Technology, Powstańców Warszawy 12, 35-959 Rzeszow, Poland

6 Centre of Polymer Systems, Tomas Bata University in Zlin, Str. T. Bati 5678, 76001 Zlín, Czech Republic 
reduced. The investigated properties of the obtained PUs with imidazoquinazoline rings were compared with those ones of suitable PUs based on 1,4-butanediol.

Graphical abstract Linear polyurethanes were obtained in reaction of 1-phenyl2,6-bis(2-hydroxyethylimidazo[1,5-c]quinazoline-3,5-dione with hexamethylene 1,6-diisocyanate, 4,4'-diphenylmethane diisocyanate and toluene 2,4-diisocyanate. Their composition and structure were confirmed. The phase contents and thermal properties were investigated
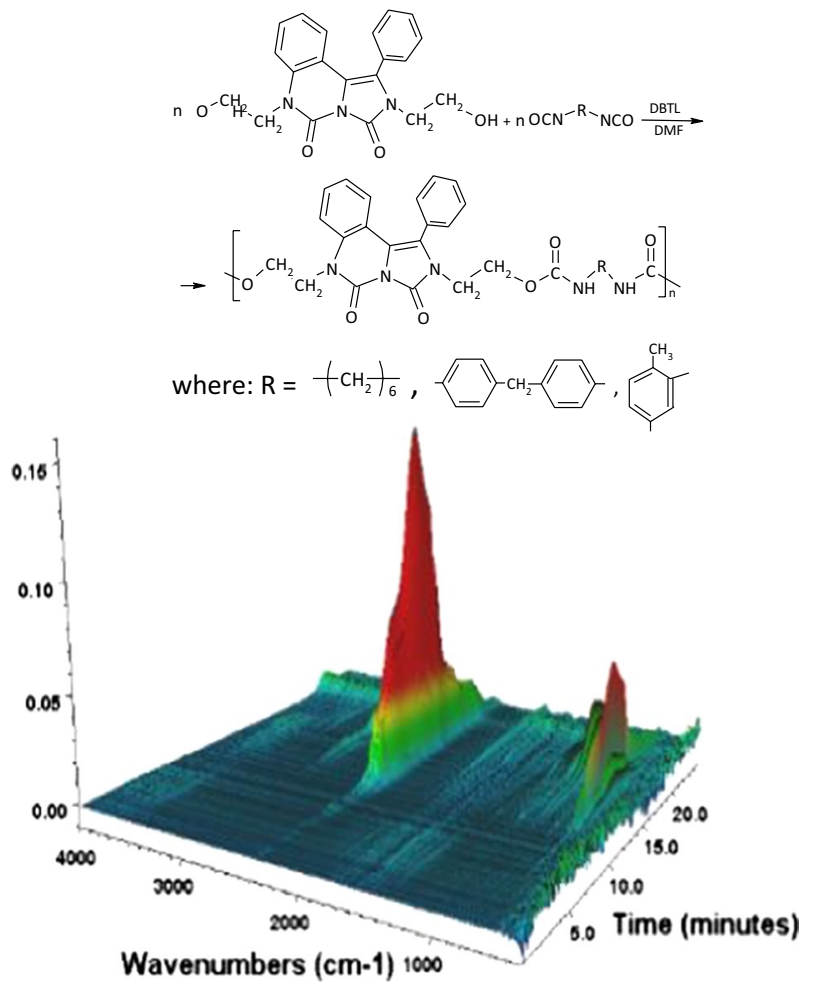

Keywords Linear polyurethanes · Imidazoquinazoline ring $\cdot$ Structure $\cdot$ Thermal properties $\cdot$ Degradation products $\cdot$ Phase content

\section{Introduction}

Polyurethanes (PUs) are one of the most significant industrial polymers. They are applied in the furniture, footwear, textiles, automotive and construction industries as well as in medicine [1-9].

From a chemical composition perspective, the $\mathrm{PUs}-\mathrm{NH}-(\mathrm{CO}) \mathrm{O}-$ can be seen as a hybrid of polyamides $-\mathrm{NH}-(\mathrm{CO})-$ and polyesters $-(\mathrm{CO}) \mathrm{O}-$. The urethane 
group includes both the amide group and the ester group, simultaneously. Nevertheless, the behavior of PUs is closer to polyamides due to their ability to form hydrogen bonds using the urethane "amide moiety." In fact, linear aliphatic PUs may be considered as derivatives of polyamides with the same number of atoms in the main chain in which one methylene group has been replaced by an oxygen atom.

However, the polyurethane's response to a water attack is much weaker than polyester or polyamide. This high hydrolysis resistance can be a disadvantage in those applications where self-destructive material is desirable. In particular, it refers the use of PUs in biomedicine, due to their very good biocompatibility [5-10].

Linear PUs are formed as a result of the polyreaction of bifunctional organic diisocyanates with diols. Linear PUs were first obtained in 1940 under the name Perlon. They have been used as foils, fibers and technical products [11]. Today, the linear PUs are one of the most important products with the large commercial tonnage production due to their physic-chemical properties and versatile applications, universal operating characteristics, ecological safety, and the ability to use new design materials with anticipated features [12-17].

Linear PUs exhibit small shrinkage, high dimensional stability, low water absorption, good chemical resistance, good abrasion resistance and high resistance to boiling water exposure. Furthermore, linear PUs characterize higher thermal stability than crosslinked ones [18-20]. On the other side, the linear PU materials obtained by the prepolymer method undergo thermal decomposition much more easier than their counterparts produced by the one-stage method [21]. Generally, hard segments (HS) in a polyurethane are usually the first to decompose. For equivalent amounts of HS, the polyurethane obtained by the prepolymer method will display longer hard segments than that obtained by the one-stage method; but if these HS are long enough to be semicrystalline they could be more stable than the amorphous HS of the one-stage sample. Thermal stability is highly dependent on the degree of microphase separation.

Unfortunately, PUs do not show too very high thermal stability. Urethane bonds start to decompose at temperature range $180-200{ }^{\circ} \mathrm{C}[22,23]$. Therefore, the properties studies including thermal properties of linear PUs are very important.

It was investigated that an incorporation of aromatic or heteroaromatic rings in the polyurethane backbone leads to higher glass transition temperature and higher time of their thermal stability [24-26].

Polyurethanes with heterocyclic structures exhibit improved both thermal and mechanical properties that are useful in many practical applications. The following heterocyclic derivatives have been used in the synthesis of polyurethanes: sulfadiazine [27], pyridine [28-30], triazine [31, 32], quinoline [33], pyrol [34], pyridazine [35], isosorbide [36-39].

Introduction of heterocyclic moieties into the main chain of the polyurethane has a significant impact on the electric properties and molecular dynamics of the polymer $[40,41]$. Heterocycles containing nitrogen have been widely investigated due to their unique properties, with possible application in building electronic devices [42, 43]. 
Also, nitrogen heterocyclic rings have long been in use in biomedical research as delivery vectors for bioactive applications due to their ability to form hydrogen bonds with drugs and proteins [44].

Polyurethane elastomer films with pyridine moieties in the main chain form photosensitive materials, which change their color over time in direct relation to storing conditions [45].

PUs with highly functional pyridine rings had substantially improved thermal stability and mechanical properties [30, 46, 47].

Polyurethanes with incorporated 1,2,3-triazole rings into backbone exhibit improved thermomechanical properties and are biocompatible [48-50].

On the other hand, PUs based on hydroxylated polyethers prepared form aromatic diacids have increased hardness and chemical resistance as well as higher glass transition temperature. However, phenyl rings are responsible for absorption of UVlights. It results in photo-oxidative degradation and yellowing of PU coatings upon outdoor exposure [51].

In turn, PUs obtained with the use of MDI and aromatic-aliphatic diols (biphenyl, benzophenone, azobenzene, azoxybenzene) show better microphase segregation [52], and better chemical resistance and lower compression set [53] compared to the analogous prepared form aliphatic diols [54, 55].

Generally, there is more and more papers involving the synthesis and properties of linear PUs [56-62].

It was also supposed that polyurethanes with imidazoquinazoline rings will exhibit interesting properties. In particular, thermal or thermomechanical properties due to the presence of condensed rings.

The paper describes the synthesis and characterization of new linear PUs with imidazoquinazoline rings. New PUs were obtained with the use of diol with imidazoquinazoline ring -2,6-bis(2-hydroxyethyl)-1-phenylimidazo[1,5-c]quinazoline3,5-dione (BHPIQ) and aliphatic and aromatic isocyanates, i.e., hexamethylene 1,6-diisocyanate (HDI), diphenylmethane 4,4'-diisocyanate (MDI) and toluene 2,4-diisocyanate (TDI). PUs have been characterized by instrumental methods, including spectral ones. Their thermal stability and thermal decomposition products were also investigated by thermogravimetry (TG and DTG) and FTIR spectroscopy, respectively. Furthermore, the thermal properties of obtained PUs were studied by standard differential scanning calorimetry (DSC) and temperature-modulated DSC (TMDSC). Wide-angle X-ray scattering (WAXS) and standard DSC methods allowed also determining the phase contents for the tested PUs.

\section{Materials and methods}

\section{Materials}

1-Phenyl-2H,6H-imidazo[1,5-c]quinazoline-3,5-dione (PIQ) was obtained according to the procedure [63]. Diphenylmethane 4,4'-diisocyanate, 98\%; hexamethylene 1,6-diisocyanate, 98\%; toluene 2,4-diisocyanate, 97\%; and dibutyltin dilaurate (DBTL), $>96 \%$ were purchased from Sigma-Aldrich, Germany. 
$N, N$-Dimethylformamide, p.a., was provided by CHEMPUR, Piekary Śląskie, Poland. Diethyl ether and 1,4-butanediol, p.a. were obtained from POCH, Gliwice, Poland. All chemicals were used as received.

\section{Analytical methods}

\section{Determination of the isocyanate group content}

Isocyanate group content was determined by the standard [64].

\section{IR spectroscopy}

IR spectra of PUs were recorded on PARAGON 1000 FTIR apparatus. Spectra were made with the resolution of the order of $0.01 \mathrm{~cm}^{-1}$. Samples were prepared in the form of potassium bromide disks.

\section{${ }^{1} \mathrm{H}$-NMR spectroscopy}

${ }^{1} \mathrm{H}-\mathrm{NMR}$ spectra of PUs were recorded on $500 \mathrm{MHz}$ spectrometer (Bruker, Germany). Deuterated dimethyl sulfoxide $\left(\mathrm{d}_{6}\right.$-DMSO) was used as solvent and hexamethyldisiloxane (HMDS) as reference.

\section{Elemental analysis}

Elemental analysis $(\mathrm{C}, \mathrm{H}, \mathrm{N})$ of PUs was performed on an elemental analyser EA 1108, produced by Carlo-Erba.

\section{Determination of molar mass of PUs by size exclusion chromatography (SEC)}

The molar mass (number-aver-age $\left(\bar{M}_{\mathrm{n}}\right)$, weight-average $\left(\bar{M}_{\mathrm{w}}\right)$ and dispersity index $\left.\mathrm{DI}=M_{\mathrm{w}} \times M_{\mathrm{n}}^{-1}\right)$ of the PUs were determined using HT-GPC 220 chromatographic system (Agilent), equipped with a dual detection set-up (refractive index and viscometric response detectors). The samples were dissolved in DMF $\left(\sim 3 \mathrm{mg} \mathrm{ml}^{-1}\right)$ overnight. Separation and detection took place on PL gel-mixed bed columns $(1 \times$ Mixed-A, $300 \times 7.8 \mathrm{~mm}, 15 \mu \mathrm{m}$ particles $+1 \times$ Mixed-B, $300 \times 7.8 \mathrm{~mm}, 10 \mu \mathrm{m}$ particles $+1 \times$ Mixed-D, $300 \times 7.8 \mathrm{~mm}, 5 \mu \mathrm{m}$ particles) at $50{ }^{\circ} \mathrm{C}$ in DMF; the flow rate equaled $1.0 \mathrm{ml} \mathrm{min}{ }^{-1}$ and injection volume was $100 \mu \mathrm{l}$. The GPC system was calibrated through universal calibration, with narrow polystyrene standards ranging 580-271,000 $\mathrm{g} \mathrm{mol}^{-1}$ (Polymer Laboratories Ltd., UK). All data processing was carried out in Cirrus software. 


\section{TG-FTIR analysis}

Thermogravimetric analyses of PUs were performed using a Mettler Toledo TGA/ DSC1 apparatus. The experiments have been carried out in the nitrogen atmosphere in the temperature range from 25 to $700{ }^{\circ} \mathrm{C}$ at a heating rate of $10{ }^{\circ} \mathrm{C} \mathrm{min}^{-1}$. The measurement conditions were as follows: sample weight $\sim 10 \mathrm{mg}$, gas flow $50 \mathrm{ml} \mathrm{min}{ }^{-1}, 150 \mu \mathrm{l}$ open alumina pan.

TG-FTIR-MS analyses of PUs were performed with the use of Mettler Toledo TGA/DSC1 instrument, which was online coupled with FTIR apparatus Nicolet iZ10 (Thermo Scientific) by a transfer line heated at $220^{\circ} \mathrm{C}$. The FTIR spectra of the evolved gases were acquired in the range of $400-4000 \mathrm{~cm}^{-1}$ with the resolution of $4 \mathrm{~cm}^{-1}$.

\section{DSC and TMDSC analysis}

Measurements were carried out using the standard differential scanning calorimetry (DSC) and temperature-modulated differential scanning calorimetry (TMDSC) of a TA Q1000 ${ }^{\mathrm{TM}}$ and a TA 2920 from TA Instruments, Inc. (New Castle, DE, USA). These calorimeters are the heat-flux type and use a mechanical refrigerator to cool the sample. All experiments were performed in a nitrogen atmosphere with a constant flow rate of around $50 \mathrm{ml} \mathrm{min}$ [65].

The series of experimental heat flow rates were obtained by standard DSC at a heating rate of $10 \mathrm{deg}$ min after previous cooling also at $10 \mathrm{deg} \mathrm{min}$. The temperature and heat flow rate calibration in the DSC apparatus was performed using parameters of melting indium $\left[T_{\mathrm{m}}\right.$ (onset) $=156.6{ }^{\circ} \mathrm{C}, \Delta H_{\mathrm{f}}=28.45 \mathrm{~J} \mathrm{~g}$ $(3.281 \mathrm{~kJ} \mathrm{~mol})$ ] [65]. Heating process for the TMDSC measurements was performed using the underlining heating rate equals $3 \mathrm{deg} \mathrm{min}$, and temperature modulation conditions as following: modulation amplitude, $A=1.5 \mathrm{deg}$ and period of modulation, $p=60 \mathrm{~s}[65,66]$.

The masses of the samples used for the DSC measurements were 10-30 mg and 3-5 mg for the TMDSC measurements. The thermal data were collected from the second heating run after controlled cooling. By the standard DSC measurements, total heat flow rate and by standard TMDSC total, reversing, and non-reversing heat flow rates as a function of time and temperature were obtained for investigated samples. All processes which are accidental and those which are irreversible are disregarded in this method and belong to non-reversing contributions of the heat flow rate $[65,66]$.

\section{X-ray analysis}

Phase composition of the polymer samples was identified using an X-ray diffractometer ARL X'TRA from Thermo Fisher company. Filtered copper lamp with a voltage of $40 \mathrm{kV}$, range $2 \theta=10^{\circ}-100^{\circ}$ and step size $0.02^{\circ} 3 \mathrm{~s}$ was used. Phase 
composition was determined using the powder diffraction file (PDF) developed and issued by The International Center for Diffraction Data (ICDD).

\section{Experimental}

\section{Synthesis of 2,6-bis(2-hydroxyethyl)-1-phenylimidazo[1,5-c] quinazoline-3,5-dione}

$5.54 \mathrm{~g}(2 \mathrm{~mol})$ of PIQ was inserted into a high pressure reactor with a volume of $100 \mathrm{~cm}^{3}$. Then, $30 \mathrm{~cm}^{3}$ of dimethylsulfoxide (DMSO), $0.02 \mathrm{~g}(0.2 \mathrm{~mol})$ triethyl-

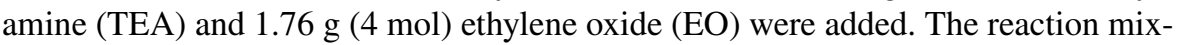
ture was heated to a temperature of $70-80{ }^{\circ} \mathrm{C}$. When the epoxy number of reaction mixture was zero, DMSO and TEA were distilled under vacuum. The product -2,6-bis(2-hydroxyethyl)-1-phenylimidazo[1,5-c] quinazoline-3,5-dione was precipitated with acetone and crystallized from ethanol.

(BHPIQ)

\section{Preparation of linear PUs with imidazoquinazoline rings}

In a $50 \mathrm{~cm}^{3}$ three-necked round-bottom flask equipped with a magnetic stirrer and a reflux condenser, $1.825 \mathrm{~g}(5 \mathrm{~mol})$ BHPIQ, $10 \mathrm{~cm}^{3}$ anhydrous $N, N$-dimethylformamide (DMF) and $0.15 \mathrm{~g}$ of DBTL were placed and heated to $90{ }^{\circ} \mathrm{C}$. The reaction was carried out under nitrogen atmosphere. After reaching a temperature of $90{ }^{\circ} \mathrm{C}$, $0.42 \mathrm{~g}(2.5 \mathrm{~mol})$ of HDI dissolved in $2.5 \mathrm{~cm}^{3}$ of DMF was added dropwise over $5 \mathrm{~min}$, and after $30 \mathrm{~min}$, the operation was repeated. The reaction mixture was kept at constant temperature for $5 \mathrm{~h}$, i.e., until the reaction was completed. The reaction progress was monitored by checking of NCO groups contents. During the reaction, when the solution viscosity was too high, more solvent (about $5 \mathrm{~cm}^{3}$ ) was added. The sticky solution was poured into $200 \mathrm{~cm}^{3}$ of cold ether. Then, it was washed with several portions of water and solvents were evaporated to dryness with the use of toluene. The product was dried to constant weight in a vacuum oven at $190{ }^{\circ} \mathrm{C}$.

Table 1 shows the sample codes of all PUs.

The synthesis conditions were optimized on the example of reaction with HDI. Finally, it was found that it is the best to introduce the diisocyanate in two portions into

Table 1 Sample codes of PUs

\begin{tabular}{lllll}
\hline Code & Isocyanate type & Diol type & Solvent & $\begin{array}{l}\text { Reaction } \\
\text { temperature } \\
\left({ }^{\circ} \mathrm{C}\right)\end{array}$ \\
\hline PU-HDI & HDI & BHPIQ & DMF & 90 \\
PU-MDI & MDI & BHPIQ & DMF & 90 \\
PU-TDI & TDI & BHPIQ & DMF & 90 \\
BU-HDI & HDI & BU & Acetone & 50 \\
BU-MDI & MDI & BU & Acetone & 50 \\
BU-TDI & TDI & BU & Acetone & 50 \\
\hline
\end{tabular}


Table 2 Reaction conditions of BHPIQ with diisocyanates

\begin{tabular}{lllll}
\hline Entry & Isocyanate type & $\begin{array}{l}\text { Amount of } \\
\text { DBTL (wt\%) }\end{array}$ & $\begin{array}{l}\text { Reaction } \\
\text { time (h) }\end{array}$ & Product symbol \\
\hline 1 & HDI & 0.03 & 5 & PU-HDI \\
2 & MDI & 0.05 & 8 & PU-MDI \\
3 & TDI & 0.10 & 24 & PU-TDI \\
4 & HDI & - & 8 & BU-HDI \\
5 & MDI & - & 4 & BU-MDI \\
6 & TDI & - & 2 & BU-TDI \\
\hline
\end{tabular}

reaction mixture. The reactions of BHPIQ with aromatic isocyanates (MDI, TDI) were carried out in analogues conditions (Table 2).

The syntheses of the rest PUs were conducted with the use of $1.25 \mathrm{~g} \mathrm{(5} \mathrm{mol)} \mathrm{of} \mathrm{MDI}$ and $0.20 \mathrm{~g}$ of DBTL or $0.87 \mathrm{~g}$ of TDI $(5 \mathrm{~mol})$ and $0.50 \mathrm{~g}$ drops of DBTL, respectively (Table 1). The products were purified by pouring, viscous solutions to $200 \mathrm{~cm}^{3}$ of cold acetone. The precipitates were filtered off and then washed with several portions of acetone and dried. The reaction conditions are given in Tables 1 and 2 .

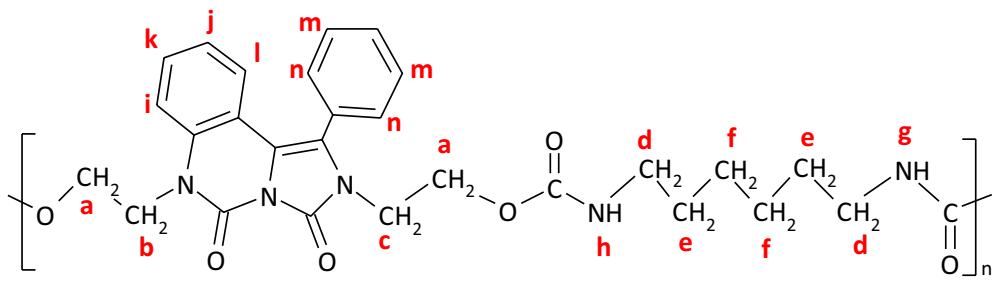

PU-HDI characterization: yield 94\%, yellowish powder; Anal. calcd. for repeating unit of PU-HDI- $\mathrm{C}_{28} \mathrm{H}_{31} \mathrm{~N}_{5} \mathrm{O}_{6}$ : C 63.03, $\mathrm{H} \mathrm{5.86,} \mathrm{N} \mathrm{12.13;} \mathrm{found:} \mathrm{62.24,} \mathrm{6.39,}$ 12.21; IR (KBr): $\nu=3332(s, \nu(\mathrm{NH})), 3058(w, \nu(\mathrm{CH}$ in $\mathrm{Ph})), 2927\left(w, \nu_{\text {as }}\left(\mathrm{CH}_{2}\right)\right)$, $2856\left(w, \nu_{\mathrm{s}}\left(\mathrm{CH}_{2}\right)\right), 1846(s, \nu(\mathrm{C}=\mathrm{O}$ in $\mathrm{NH}(\mathrm{CO}) \mathrm{O})), 1754(s, \nu(\mathrm{C}=\mathrm{O}$ in rings $)), 1666$, 1604, 1504, $1445\left(s, \nu\right.$ of Ph ring), $1133\left(w, d_{\mathrm{p}}(\mathrm{C}-\mathrm{H})\right), 752,698\left(s, d_{\mathrm{np}}(\mathrm{C}-\mathrm{H})\right), 1650$, 1579, 1486 ( $s, \nu$ of quinazoline ring), 1258 and $1238\left(s, \nu_{\text {as }}(\mathrm{C}-\mathrm{O}\right.$ in $\left.\mathrm{NH}(\mathrm{CO}) \mathrm{O})\right)$, 1133 and $1105\left(s, \nu_{\mathrm{s}}(\mathrm{C}-\mathrm{O}\right.$ in $\left.\mathrm{NH}(\mathrm{CO}) \mathrm{O})\right)\left[\mathrm{cm}^{-1}\right]$; ${ }^{1} \mathrm{H}-\mathrm{NMR}\left(500 \mathrm{MHz}, \mathrm{d}_{6}\right.$-DMSO, $\delta)=1.21\left(4 \mathrm{H}, \mathrm{f},-\mathrm{C}-\mathrm{CH}_{2}\right), 1.31\left(4 \mathrm{H}, \mathrm{e},-\mathrm{C}-\mathrm{CH}_{2}\right), 2.93\left(4 \mathrm{H}, \mathrm{d},-\mathrm{N}-\mathrm{CH}_{2}\right), 3.63(2 \mathrm{H}$, c, $\left.-\mathrm{N}-\mathrm{CH}_{2}\right), 4.01\left(2 \mathrm{H}, \mathrm{b},-\mathrm{N}-\mathrm{C}_{2}\right), 4.20\left(4 \mathrm{H}, \mathrm{a},-\mathrm{O}-\mathrm{CH}_{2}\right), 7.10(1 \mathrm{H}, \mathrm{g},-\mathrm{NH}), 7.35$ $(1 \mathrm{H}, \mathrm{h},-\mathrm{NH}), 6.80(1 \mathrm{H}, \mathrm{i}, \mathrm{CH}), 6.90(1 \mathrm{H}, \mathrm{j}, \mathrm{CH}), 7.15(1 \mathrm{H}, \mathrm{k}, \mathrm{CH}), 7.25(1 \mathrm{H}, 1$, $\mathrm{CH}), 7.50$ (2H, m, CH), 7.60 (3H, n, CH), [ppm]. 


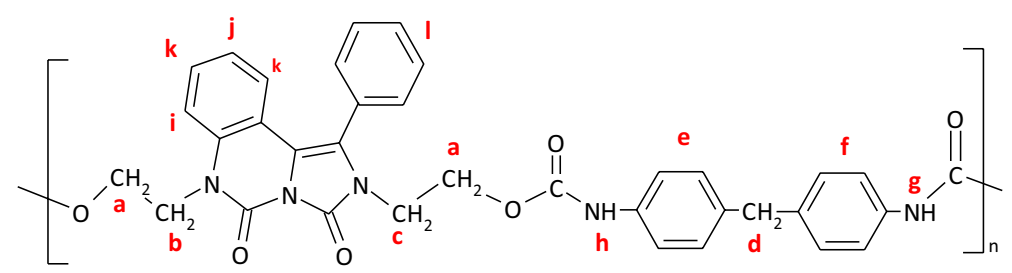

PU-MDI characterization: yield 92\%, yellowish powder; Anal. calcd. for repeating unit of PU-MDI- $\mathrm{C}_{35} \mathrm{H}_{29} \mathrm{~N}_{5} \mathrm{O}_{6}$ : C 68.29, $\mathrm{H}$ 4.75, N 11.38; found C 68.61, H 5.17, $\mathrm{N} 10.65$; IR (KBr): $\nu=3417(s, \nu(\mathrm{NH})), 3028(w, \nu(\mathrm{CH}$ in $\mathrm{Ph})), 2981\left(w, \nu_{\text {as }}\left(\mathrm{CH}_{2}\right)\right)$, $2971\left(w, \nu_{\mathrm{s}}\left(\mathrm{CH}_{2}\right)\right), 1754(s, \nu(\mathrm{C}=\mathrm{O}$ in $\mathrm{NH}(\mathrm{CO}) \mathrm{O})$ and in rings $\left.)\right), 1660,1601,1513$, $1444\left(s, \nu\right.$ of $\mathrm{Ph}$ ring), $1112\left(w, d_{\mathrm{p}}(\mathrm{C}-\mathrm{H})\right), 751,696\left(s, d_{\mathrm{np}}(\mathrm{C}-\mathrm{H})\right), 1650,1559,1485$ $\left(s, \nu\right.$ of quinazoline ring), 1261 and $1218\left(s, \nu_{\text {as }}(\mathrm{C}-\mathrm{O}\right.$ in $\left.\mathrm{NH}(\mathrm{CO}) \mathrm{O})\right), 1073\left(s, \nu_{\mathrm{s}}\right.$ $(\mathrm{C}-\mathrm{O}$ in $\mathrm{NH}(\mathrm{CO}) \mathrm{O})$ ) $\left[\mathrm{cm}^{-1}\right]$; ${ }^{1} \mathrm{H}-\mathrm{NMR}\left(500 \mathrm{MHz}, \mathrm{d}_{6}-\mathrm{DMSO}, \delta\right)=3.62(2 \mathrm{H}, \mathrm{c}$, $\left.-\mathrm{N}-\mathrm{CH}_{2}\right), 3.76\left(2 \mathrm{H}, \mathrm{d},-\mathrm{CH}_{2}\right), 4.12\left(2 \mathrm{H}, \mathrm{b},-\mathrm{N}-\mathrm{C}_{2}\right), 4.33\left(4 \mathrm{H}, \mathrm{a},-\mathrm{O}-\mathrm{C}_{2}\right), 6.70$ $(1 \mathrm{H}, \mathrm{i}, \mathrm{CH}), 6.80(1 \mathrm{H}, \mathrm{j}, \mathrm{CH}), 7.10(4 \mathrm{H}, \mathrm{e}, \mathrm{CH}), 7.15-7.40(7 \mathrm{H}, \mathrm{k}, 1, \mathrm{CH}), 7.50(4 \mathrm{H}$, f, $\mathrm{CH},), 9.45(1 \mathrm{H}, \mathrm{g},-\mathrm{NH}), 9.57(1 \mathrm{H}, \mathrm{h},-\mathrm{NH}),[\mathrm{ppm}]$.<smiles></smiles>

PU-TDI characterization: yield $90 \%$, yellowish powder; Anal. calcd. for repeating unit of PU-TDI- $\mathrm{C}_{29} \mathrm{H}_{25} \mathrm{~N}_{5} \mathrm{O}_{6}$ : C 64.56, H 4.67, N 11.98; C 64.35, H 4.98, N 11.66; IR (KBr): $\nu=3330(s, \nu(\mathrm{NH})), 3056(w, \nu(\mathrm{CH}$ in $\mathrm{Ph})), 2957\left(w, \nu_{\text {as }}\left(\mathrm{CH}_{2}\right)\right), 2925$ $\left(w, \nu_{\mathrm{s}}\left(\mathrm{CH}_{2}\right)\right.$ and $\left.\nu_{\mathrm{as}}\left(\mathrm{CH}_{3}\right)\right), 2855\left(w, \nu_{\mathrm{s}}\left(\mathrm{CH}_{3}\right)\right), 1754(s, \nu(\mathrm{C}=\mathrm{O}$ in $\mathrm{NH}(\mathrm{CO}) \mathrm{O})$ and in rings $)$, 1664, 1603, 1533, $1445(s, \nu$ of $\mathrm{Ph}$ ring $), 1130\left(w, d_{\mathrm{p}}(\mathrm{C}-\mathrm{H})\right), 752,698$ $\left(s, d_{\mathrm{np}}(\mathrm{C}-\mathrm{H})\right), 1650,1550,1486\left(s, \nu\right.$ of quinazoline ring), 1261 and $1225\left(s, \nu_{\mathrm{as}}\right.$ $(\mathrm{C}-\mathrm{O}$ in $\mathrm{NH}(\mathrm{CO}) \mathrm{O})), 1076\left(s, \nu_{\mathrm{s}}(\mathrm{C}-\mathrm{O}\right.$ in $\left.\mathrm{NH}(\mathrm{CO}) \mathrm{O})\right),\left[\mathrm{cm}^{-1}\right]$; ${ }^{1} \mathrm{H}-\mathrm{NMR}(500 \mathrm{MHz}$, $\mathrm{d}_{6}$-DMSO, $\left.\delta\right)=2.05\left(3 \mathrm{H}, \mathrm{d},-\mathrm{CH}_{3}\right), 3.65\left(2 \mathrm{H}, \mathrm{c},-\mathrm{N}-\mathrm{CH}_{2}\right), 4.15\left(2 \mathrm{H}, \mathrm{b},-\mathrm{N}-\mathrm{CH}_{2}\right)$, $4.35\left(4 \mathrm{H}, \mathrm{a},-\mathrm{O}-\mathrm{CH}_{2}\right), 6.75(1 \mathrm{H}, \mathrm{i}, \mathrm{CH}), 6.80(1 \mathrm{H}, \mathrm{j}, \mathrm{CH}), 7.00(1 \mathrm{H}, \mathrm{f}, \mathrm{CH}), 7.15$ $(1 \mathrm{H}, \mathrm{l}, \mathrm{CH}), 7.25(1 \mathrm{H}, \mathrm{k}, \mathrm{CH}), 7.30(1 \mathrm{H}, \mathrm{e}, \mathrm{CH}), 7.55(5 \mathrm{H}, \mathrm{m}, \mathrm{n}, \mathrm{CH}), 8.85(1 \mathrm{H}, \mathrm{g}$, $-\mathrm{NH}), 9.55$ (1H, h, -NH), [ppm].

\section{Preparation of linear PUs based on butane-1,4-diol}

$4.50 \mathrm{~g}$ (0.05 mol) 1,4-butanediol (BU), $0.05 \mathrm{~mol}$ of suitable diisocyanate: $8.40 \mathrm{~g}$ HDI or $12.50 \mathrm{~g}$ MDI or $8.70 \mathrm{~g}$ TDI, and $25 \mathrm{~cm}^{3}$ acetone were placed in three-necked, 
$100 \mathrm{~cm}^{3}$ round-bottom flask equipped with mechanical stirrer, reflux condenser and thermometer. Reaction was carried out in the nitrogen atmosphere. Temperature of the solution was maintained app. $50{ }^{\circ} \mathrm{C}$. Progress of reaction was monitored by determination of isocyanate group content. When reaction was completed, the solvent was evaporated and solid residue was dried to constant mass $\left(t=60{ }^{\circ} \mathrm{C}\right.$, $p=2 \times 10^{-3} \mathrm{MPa}=15 \mathrm{~mm} \mathrm{Hg}$ ).

It was obtained three PUs denoted as BU-HDI, BU-MDI, BU-TDI, respectively (Table 1).

\section{Results and discussion}

\section{Synthesis conditions of linear PUs with imidazoquinazoline rings}

In order to obtain linear PUs with imidazoquinazoline rings, 1-phenyl-2,6-bis(2hydroxyethyl)imi-dazo[1,5-c] quinazoline-3,5-dione (BHPIQ) was reacted with following diisocyanates: hexamethylene 1,6-diisocyanate (HDI), diphenylmethane 4,4'-diisocyanate (MDI) and toluene 2,4-diisocyanate (TDI) (Fig. 1).

It has been observed that BHPIQ had the shortest reaction time with HDI. Aromatic isocyanates reacted more slowly, in the following order: MDI and then TDI (Table 2, entry 1-3). The reactivity of diisocyanates with BHPIQ was the opposite of the typical reactivity of diisocyanates with alcohols. Typically, aromatic diisocyanates exhibit higher reactivity than aliphatic ones and TDI is more reactive than MDI [67, 68].

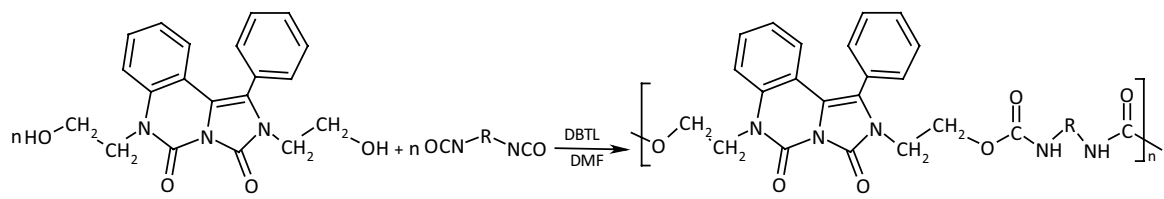

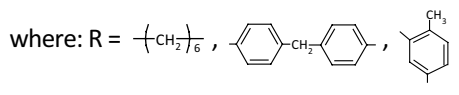

Fig. 1 Synthesis scheme of linear PUs with imidazoquinazoline rings

Table 3 Results of elemental analysis of the obtained linear PUs

\begin{tabular}{|c|c|c|c|c|c|c|}
\hline \multirow[t]{2}{*}{ Product } & \multicolumn{2}{|l|}{$\mathrm{C}(\mathrm{wt} \%)$} & \multicolumn{2}{|l|}{$\mathrm{H}(\mathrm{wt} \%)$} & \multicolumn{2}{|l|}{$\mathrm{N}(\mathrm{wt} \%)$} \\
\hline & Calculated & Found & Calculated & Found & Calculated & Found \\
\hline PU-HDI & 63.03 & 62.24 & 5.86 & 6.39 & 12.13 & 12.21 \\
\hline PU-MDI & 68.29 & 68.61 & 4.75 & 5.17 & 11.38 & 10.65 \\
\hline PU-TDI & 64.56 & 63.35 & 4.67 & 5.18 & 11.98 & 11.66 \\
\hline BU-HDI & 55.81 & 56.15 & 8.59 & 8.64 & 10.84 & 10.76 \\
\hline BU-MDI & 67.05 & 66.56 & 5.92 & 5.76 & 8.23 & 8.33 \\
\hline BU-TDI & 59.09 & 59.39 & 6.10 & 5.95 & 10.60 & 10.85 \\
\hline
\end{tabular}


In the case of BHPIQ reactions with isocyanates, the reverse reactivity of diisocyanates was observed in relation to the expected. It was due to spatial reasons, and precisely due to the construction of the diol used. The presence of an imidazoquinazoline ring with a phenyl substituent located at a strictly defined angle to the plane of the imidazoquinazoline ring resulted in a high stiffening of the diol molecule. Therefore, BHPIQ reacted easier with an aliphatic diisocyanate, which did not contain aromatic rings and did not cause additional steric hindrance, which could interfere with the reacting hydroxyethyl groups with the isocyanate. A higher reactivity MDI than TDI could be also explained by the increased steric hindrance. The arrangement of the isocyanate groups on the opposite sides of the MDI molecule allowed the reaction to be easier than the location of the two isocyanate groups at one benzene ring of TDI.

Simultaneously, in order to compare the imidazoquinazoline rings presence on the polyurethane properties, PUs based on BU with the use of HDI, MDI and TDI were prepared (Table 2, entry 4-6).

All PUs were obtained as powdered cream products. Their composition was confirmed by elemental analysis which results are juxtapositioned in Table 3 . The calculated contents of carbon, hydrogen and nitrogen were in accordance with the found ones.

\section{Spectral characterization of linear PUs with imidazoquinazoline rings}

The structure of the obtained products was analyzed by ${ }^{1} \mathrm{H}-\mathrm{NMR}$ and IR spectroscopies. The structure characterization of PUs with imidazoquinazoline rings was discussed on the example of the reaction product of BHPIQ with MDI which structure is presented in Fig. 2. Its ${ }^{1} \mathrm{H}-\mathrm{NMR}$ spectrum was illustrated in Fig. 3.

In the ${ }^{1} \mathrm{H}-\mathrm{NMR}$ spectrum of the PU-MDI (Fig. 3), low-intensity signals were observed at 4.8 and $4.9 \mathrm{ppm}$, i.e., within the proton range of the diol hydroxyl groups. These signals derived from the hydroxyl groups forming the ends of the polymer chains. The presence of two signals was related to the magnetic inequality of the hydroxyl groups of the starting diol.

Protons of carbamate groups were also unequal and appeared in the form of two signals at 9.50 and $9.55 \mathrm{ppm}$, proton $\mathrm{h}$ and $\mathrm{g}$, respectively. The proton signal of the methylene groups a linked to oxygen atoms of the carbamate groups appeared at $4.30 \mathrm{ppm}$. The remaining methylene groups_-protons b and c derived

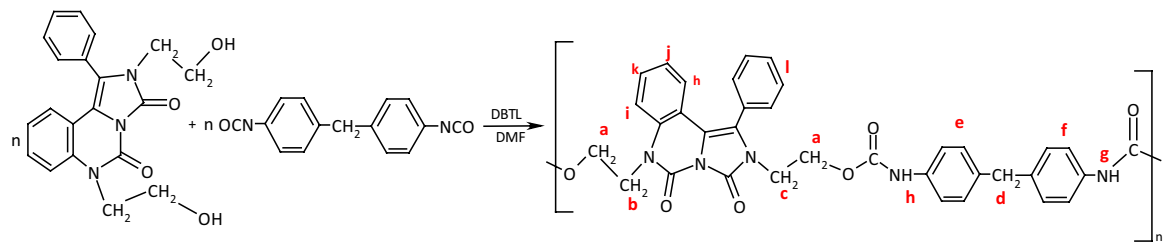

Fig. 2 Scheme of PU-MDI synthesis 
$\mathbf{a}$

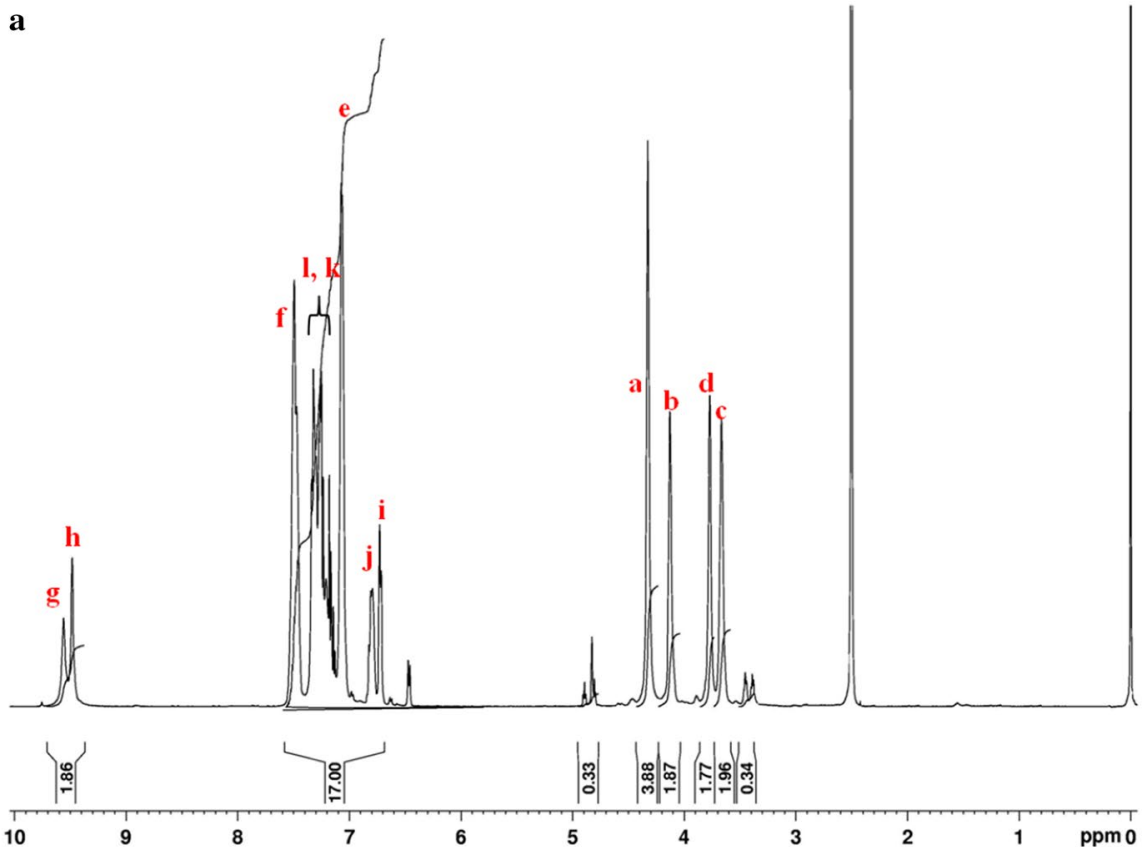

b

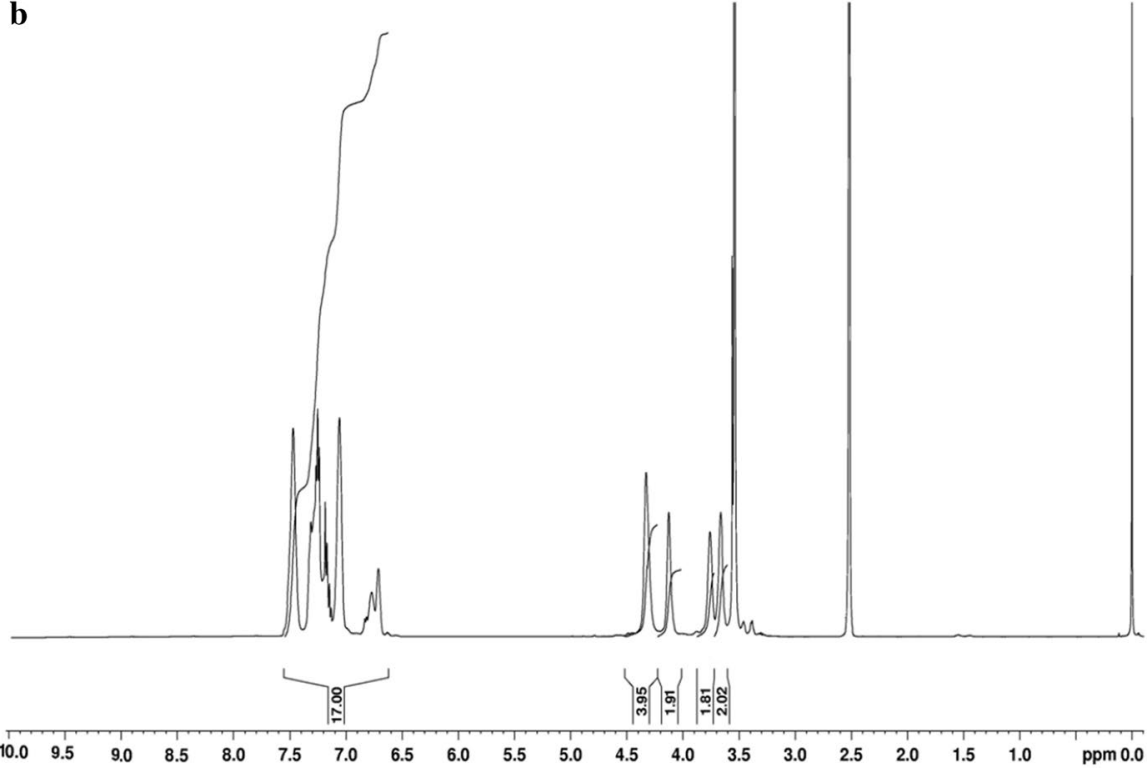

Fig. $3{ }^{1} \mathrm{H}-\mathrm{NMR}$ spectrum of PU-MDI: a without $\mathrm{D}_{2} \mathrm{O}$, b with $\mathrm{D}_{2} \mathrm{O}$

from the diol structure appeared at a chemical shift of 4.1 and $3.7 \mathrm{ppm}$, respectively. In turn, protons $d$ of the methylene group from the MDI fragment were 

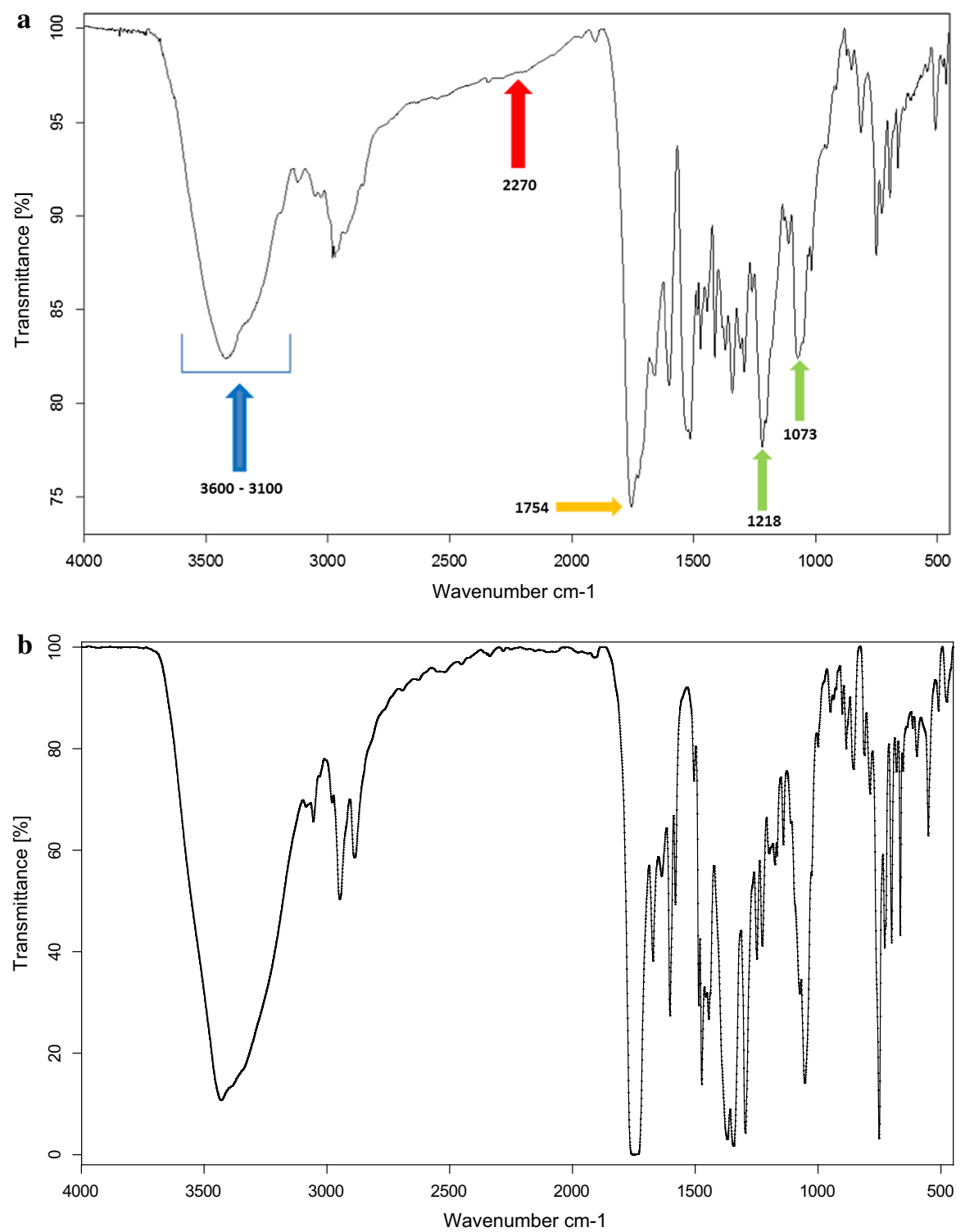

Fig. 4 IR spectrum of: a PU-MDI, b BHPIQ

located at $3.8 \mathrm{ppm}$. In addition, the signals of the quinazoline ring protons $i$ and $j$ were clearly separated and were located at 6.8 and $6.9 \mathrm{ppm}$. In turn, the protons e and $f$ of the phenyl rings of MDI were visible at 7.10 and $7.50 \mathrm{ppm}$. The protons 1 of the phenyl ring in the BHPIQ fragment and the remaining protons of the quinazoline ring $\mathrm{k}$ were visible in the range of 7.15-7.40 ppm. 

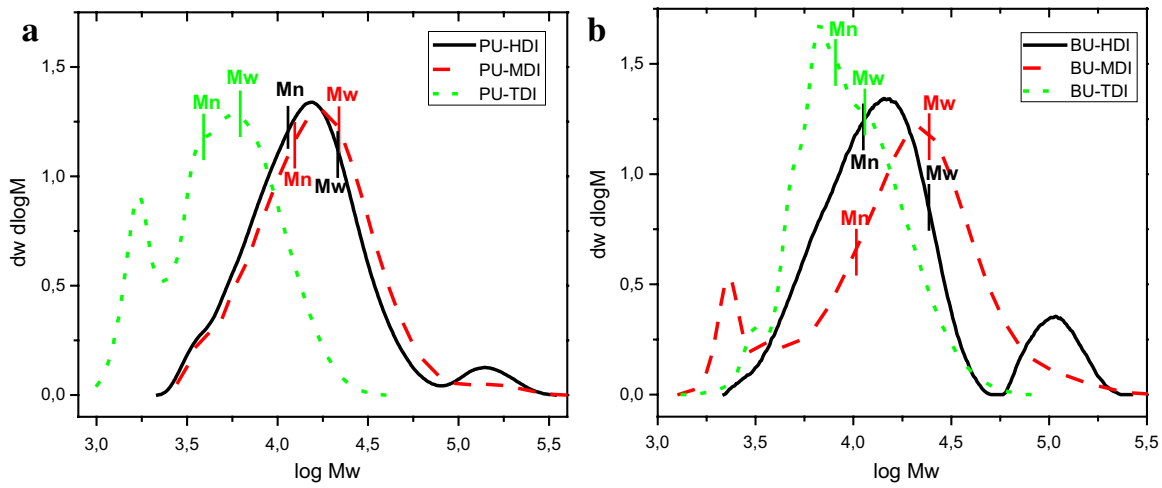

Fig. 5 The molar masses distribution of PUs based on: a BHPIQ, b BU. Results of the size exclusion chromatography (SEC) measurements $\left(M_{\mathrm{w}}\right.$ is the weight- average molar mass) $M_{\mathrm{n}}$ is the number average molar mass); $M_{\mathrm{w}} / M_{\mathrm{n}}$ is the molar mass dispersity.

Table 4 Molar masses and molar mass distributions of linear PUs

\begin{tabular}{lccl}
\hline PU & $M_{\mathrm{n}}(\mathrm{g} / \mathrm{mole})$ & $M_{\mathrm{w}}(\mathrm{g} /$ mole $)$ & $\begin{array}{l}\text { Molar mass dis- } \\
\text { persity }=M_{\mathrm{w}} / M_{\mathrm{n}}\end{array}$ \\
\hline PU-HDI & 11,400 & 21,400 & 1.9 \\
PU-MDI & 12,500 & 21,600 & 1.7 \\
PU-TDI & 3900 & 6200 & 1.6 \\
BU-HDI & 11,300 & 24,000 & 2.1 \\
BU-MDI & 10,400 & 24,700 & 2.4 \\
BU-TDI & 8100 & 11,400 & 1.4 \\
\hline
\end{tabular}

The IR spectrum of the resulting PU-MDI polyurethane shown in Fig. 4 confirmed the complete conversion of the isocyanate. No band was observed at $2270 \mathrm{~cm}^{-1}$ from the valence vibration of isocyanate groups in the spectrum.

In addition, the band shape in the range of $3600-3100 \mathrm{~cm}^{-1}$ was varied compared to the IR spectrum of BHPIQ because the N-H carbamate valence band appeared (Fig. 4). A valence vibration band of carbonyl groups was at $1754 \mathrm{~cm}^{-1}$. The symmetrical and asymmetrical vibration bands of the $\mathrm{C}-\mathrm{O}$ bonds of the carbamate groups were observed at 1218 and $1073 \mathrm{~cm}^{-1}$, respectively.

The exact spectral characteristics of the remaining PUs with imidazoquinazoline rings were described in the Experimental part. Here, it has been only mentioned that the carbamate protons of the PU-TDI were visible in the ${ }^{1} \mathrm{H}-\mathrm{NMR}$ spectrum in a similar range of $\delta$ ppm like in the PU-MDI spectrum (Fig. 3), i.e., at about 9.0 and $9.5 \mathrm{ppm}$. In the ${ }^{1} \mathrm{H}-\mathrm{NMR}$ spectrum of PU-HDI, the carbamate proton signals overlapped with the quinazoline ring protons in the range of 7.0-7.5 ppm.

The structure of PUs based on BU was confirmed by spectroscopic methods, but it was not described in the work because it is generally known. 


\section{Molar masses of linear PUs}

In order to evaluate the polymerization degree, SEC measurements were carried out and the molar masses distribution for the obtained PUs were measured and compared. It was illustrated in Fig. 5a, b. Two PUs with imidazoquinazoline ringsaliphatic and aromatic polyurethane PU-HDI and PU-MDI possessed a narrow unimodal and moderately symmetrical distribution with a molar mass dispersity of about 1.7-1.9 [-]. In turn, PU-TDI performed bimodal shape of the distribution shifted to lower values of molar masses and a bit smaller molar mass dispersity of about $1.6[-]$ (Table 4).

PU-HDI and PU-MDI had higher molar masses $\left(M_{\mathrm{w}}=21,500 \mathrm{~g} / \mathrm{mole}\right.$, and $M_{\mathrm{n}}=11,400$ and $12,500 \mathrm{~g} / \mathrm{mole}$, respectively), what allowed to belong them to polymers (Table 4) [61, 69-71]. In turn, molar masses of PU-TDI were smaller $\left(M_{\mathrm{w}}=6200 \mathrm{~g} / \mathrm{mole}\right.$ and $\left.M_{\mathrm{n}}=3900 \mathrm{~g} / \mathrm{mole}\right)$; thus, it had to be treated as oligourethane.

In the case of PUs based on BU, BU-TDI had unimodal distribution with molar mass dispersity of about 1.4 [-]. However, BU-HDI and BU-MDI possessed bimodal distribution shifted to higher values of molar masses. Their molar mass dispersity was about 2.1-2.4 [-]. PUs based on BU and HDI or MDI had also higher molar masses $\left(M_{\mathrm{w}}\right.$ higher than 20,000 g/mole). BU-TDI had smaller molar mass, $M_{\mathrm{w}}=11,400 \mathrm{~g} / \mathrm{mole}$, and thus also higher than 10,000 g/mole (Table 4).

\section{WAXS studies of linear PUs}

Most linear PUs according to the literature [72] have been semicrystalline polymers with high molar masses, high degree crystallinity, and high melting point. Generally, HDI and MDI have had a symmetrical structure, which made HDI- and MDI-based PUs easily crystallized [73-75]. In turn, TDI-based PUs have been expected to be amorphous materials.

The X-ray diffraction data, shown in Fig. 6, indicated a distinct crystalline structure only BU-HDI and BU-MDI. In Fig. 6a, we could see the appearance of very sharp
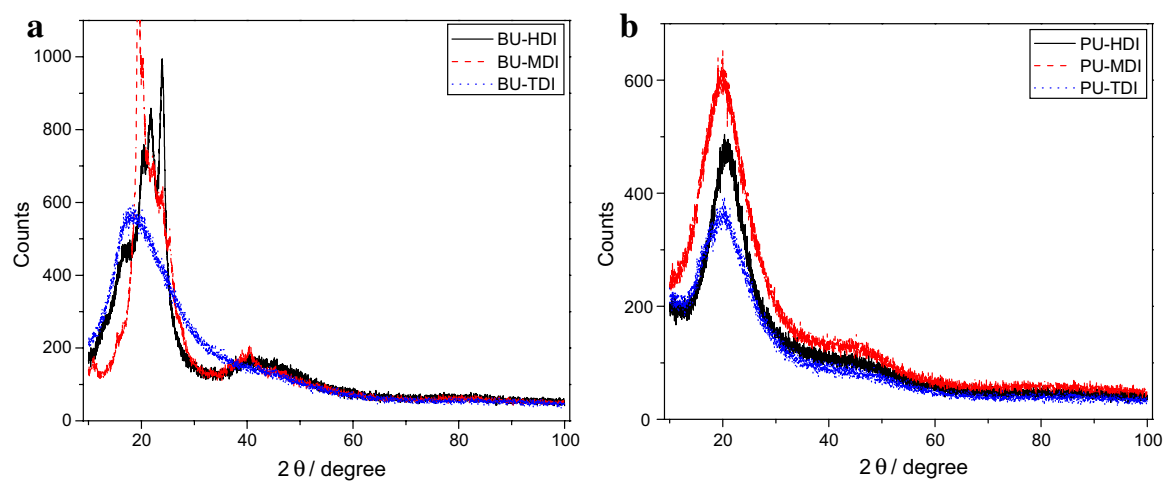

Fig. 6 WAXS diffractograms of linear PUs based on: a BU, b BHPIQ 
Fig. 7 Total and reversing heat flow rates versus temperature for BU-HDI and PU-HDI obtained based on DSC and TMDSC, respectively

Fig. 8 Dependence of heat flow rate on temperature for BU-MDI and PU-MDI obtained based on the DSC method
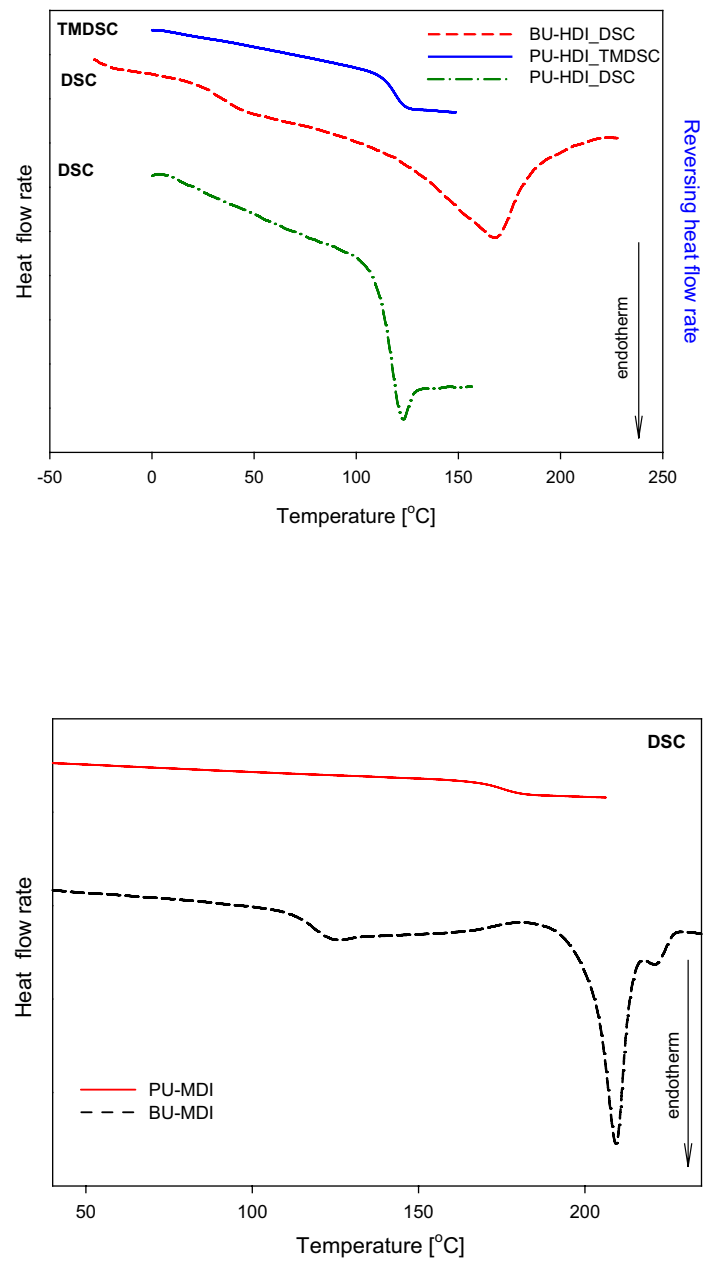

peaks in the range of $2 \theta=20^{\circ}-24^{\circ}$, corresponding to $d$-spacings of $1.89-2.25 \AA$. However, there was broad peak in the range of $2 \theta=30^{\circ}-55^{\circ}$. These results pointed to the semicrystalline character of these polymers.

Introduction of 1-phenylimidazo[1,5-c] quinazoline rings in the polyurethane structure has disturbed the symmetry of the molecule. Two broad peaks were observed in diffractograms of all PUs based on BHPIQ as shown in Fig. 6b. First one was visible in the region of $2 \theta=13^{\circ}-30^{\circ}$ with high intensity and second one with much lower intensity in the region of $30^{\circ}-60^{\circ}$. The X-ray diffraction pattern all of them was the same. Thus, all PUs based on BHPIQ and polyurethane BU-TDI showed amorphous character.

The X-ray diffraction data of the PUs were further confirmed by DSC and TMDSC studies. 
Fig. 9 Comparison of reversing heat flow rate vs temperature for PU-HDI, PU-MDI, and PU-TDI by TMDSC

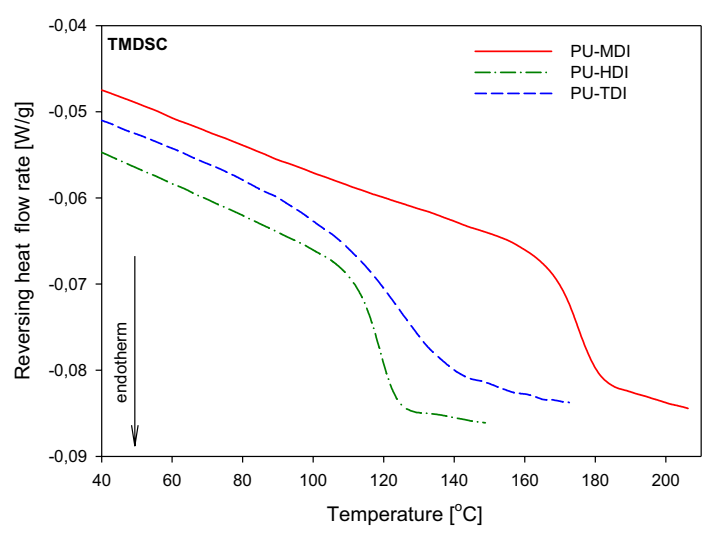

Fig. 10 Comparison of the heat flow rate $v s$ temperature for BUTDI and PU-TDI obtained based on DSC

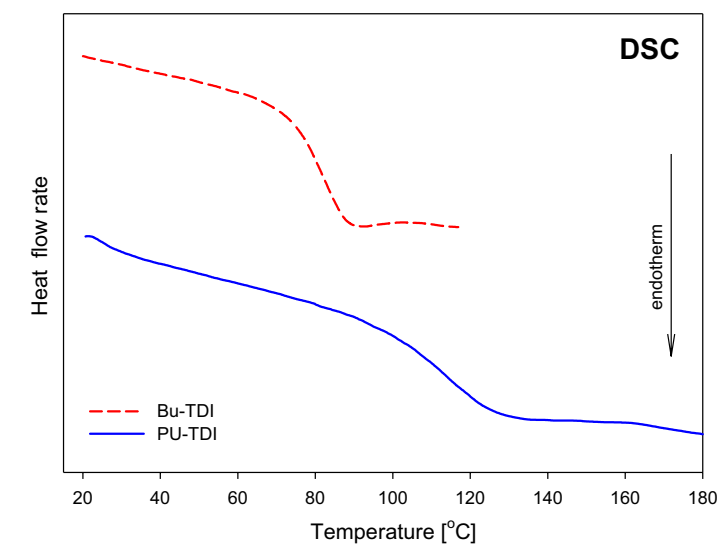

\section{Thermal properties of polyurethane materials}

Thermal properties of the obtained linear PUs based on the BU and BHPIQ were studied by DSC and TMDSC methods.

Figures 7, 8, 9 and 10 presented the comparison of heat flow rate versus temperature for the obtained PUs based on BHPIQ and the following diisocyanates, i.e., HDI, MDI, and TDI with the typical PUs obtained based on the 1,4-butanediol and the same abovementioned diisocyanates.

Figure 7 shows the results obtained based on the standard DSC and TMDSC methods for PU-HDI and BU-HDI. In the case of BU-HDI, the semicrystalline material was observed from DSC measurement. There was visible the glass transition and melting processes. The glass transition occurred at $T_{\mathrm{g}}=32.2{ }^{\circ} \mathrm{C}$ and the change of heat capacity $\Delta C_{\mathrm{p}}$ at $T_{\mathrm{g}}$ equaled $12.11 \mathrm{~J}^{\circ} \mathrm{C}^{-1} \mathrm{~mol}^{-1}$. Melting was characterized using the following thermal parameters: heat of fusion, $\Delta H_{\mathrm{f}}=4.15 \mathrm{~kJ} \mathrm{~mol}^{-1}$ and melting temperature, $T_{\mathrm{m}}$ (onset) $=109.6{ }^{\circ} \mathrm{C}$, $T_{\mathrm{m}}($ peak $)=169.4^{\circ} \mathrm{C}$. 
In the case of the BHPIQ application in the PU matrix instead of 1,4-butanediol, the change in ordering of material was observed. The amorphous material was visible for PU-HDI. The change in ordering between BU-HDI and PU-HDI was related to easy crystallization in the case of the symmetrical particles [39]. Figure 7 shows the glass transition together with the overlapping enthalpy relaxation in $T_{\mathrm{g}}$ for PUHDI_DSC obtained based on the DSC. In order to eliminate the influence of the physical aging process, the TMDSC method was applied for PU-HDI sample. Based on this result, total heat flow rate was separated into reversing and non-reversing components. From reversing heat flow rate presented in Fig. 7, thermal parameters of glass transition were estimated, i.e., temperature of glass transition, $T_{\mathrm{g}}=118.3^{\circ} \mathrm{C}$, and the change of heat capacity, $\Delta C_{\mathrm{p}}=156.41 \mathrm{~J} \mathrm{~mol}^{-1}{ }^{\circ} \mathrm{C}^{-1}$ at $T_{\mathrm{g}} . \mathrm{In}$ Fig. 7 , it could see that the presence of BHPIQ in the linear PUs caused elevation of the glass transition temperature of full amorphous sample in reference to semicrystalline BU-HDI.

Figure 8 presented the DSC thermogram of amorphous PU-MDI and semicrystalline BU-MDI. Inability to crystallization of PU-MDI compared to PU-HDI resulted from too high rigidity of the chain in the case of polyurethane based on BHPIQ and MDI. Rigidity was caused by the presence of imidazoquinazoline rings and phenyl groups in the PU structure. Furthermore, repeating unit of PU-MDI was also asymmetrical because of phenylimidazoquinazoline ring.

For semicrystalline BU-MDI (see Fig. 8) in glass transition region, the value of $T_{\mathrm{g}}=117^{\circ} \mathrm{C}$ and the change of heat capacity at $T_{\mathrm{g}}$ equaled $58.67 \mathrm{~J} \mathrm{~mol}^{-1}{ }^{\circ} \mathrm{C}^{-1}$. For the melting process, the heat of fusion, $\Delta H_{\mathrm{f}}=4.46 \mathrm{~kJ} \mathrm{~mol}^{-1}$ and onset melting temperature, $T_{\mathrm{m}}$ (onset) $=202{ }^{\circ} \mathrm{C}$ were estimated. Increased the glass transition temperature of PU-MDI compared to BU-MDI, additionally confirmed higher stiffness of PUs with imidazoquinazoline rings.

Figure 9 shows the comparison of dependence of the reversing heat flow rate on temperature for PU-HDI, PU-MDI, and PU-TDI obtained by TMDSC. In all cases, there only were visible the glass transitions. This kind of phase transition indicated amorphous nature of materials and confirmed results obtained by WAXS (Fig. 6).

Results of the reversing heat flow rate versus temperature were carried out using TMDSC because this method allowed to eliminate the physical aging in the glass transition region as it was mentioned early. In Table 5, the comparison of the thermal parameters (temperature of glass transition $\left(T_{\mathrm{g}}\right)$ and changed of heat capacity $\Delta C_{\mathrm{p}}$ at $T_{\mathrm{g}}$ ) for obtained PUs based on BHPIQ was listed. The highest value of $T_{\mathrm{g}}$ was visible for PU-MDI, and this is result of the presence of two phenylene groups in the MDI particles. The lowest glass transition temperature was noted for PU-HDI, and this is due to the presence of the flexible aliphatic chain in the HDI segment.

Table 5 Comparison of thermal parameters of PUs based on BHPIQ

\begin{tabular}{llll}
\hline Name of PU & $T_{\mathrm{g}}\left({ }^{\circ} \mathrm{C}\right)$ & $\Delta C_{\mathrm{p}}\left(\mathrm{J} \mathrm{mol}^{-1}{ }^{\circ} \mathrm{C}^{-1}\right)$ & $\begin{array}{l}\text { Num- } \\
\text { ber of } \\
\text { "beads" }\end{array}$ \\
\hline PU-HDI & 118.34 & 156.41 & $14-15$ \\
PU-MDI & 174.3 & 170.62 & $15-16$ \\
PU-TDI & 122.2 & 161.45 & $14-15$ \\
\hline
\end{tabular}


The biggest jump of heat capacity, $\Delta C_{\mathrm{p}}$ at $T_{\mathrm{g}}$ was noted for PU-MDI and was related with the presence of the biggest number of groups able to conformation (rotation) in the repeating units of investigated PU. According to Wunderlich [65, 76], each mobile unit in the chain of a polymer macromolecule contributes around $11 \mathrm{~J}^{\circ} \mathrm{C}^{-1} \mathrm{~mol}^{-1}$ to the change of heat capacity at $T_{\mathrm{g}}$. The value of $11 \mathrm{~J}^{\circ} \mathrm{C}^{-1} \mathrm{~mol}^{-1}$ was an average value and depends on the bonds which were naturally different between different kinds of atoms. The ratio of our measured heat capacity increment $\left(\Delta C_{\mathrm{p}}\right)$ to the contribution of a single mobile unit $\left(11 \mathrm{~J}^{\circ} \mathrm{C}^{-1} \mathrm{~mol}^{-1}\right)$ allowed an estimation to be made of the total number of mobile units ("beads") in amorphous materials $[65,77,78]$. This ratio gave a total of 15-16 mobile units ("beads") of PU-MDI, which start to become mobile at the glass transition. In other cases, the number of beads equaled 14-15 (see Table 5).

In Fig. 10, two amorphous materials (BU-TDI, PU-TDI) were presented. The BU-TDI was unable to crystallization because it was characterized by irregular structure of chain (asymmetrical structure of TDI). Additionally, increased rigidity of the PU-TDI chains was also observed in relation to BU-TDI. The change heat capacity $\left(\Delta C_{\mathrm{p}}\right)$ of BU-TDI equaled $126.38 \mathrm{~J} \mathrm{~mol}^{-1}{ }^{\circ} \mathrm{C}^{-1}$ at $T_{\mathrm{g}}=81.8^{\circ} \mathrm{C}$.

Results of thermal analysis of amorphous PU-TDI are also presented in Fig. 9 and Table 5 .

Fig. 11 TG (a) and DTG (b) curves of unmodified PUs recorded at heating rate $10{ }^{\circ} \mathrm{C} \mathrm{min}{ }^{-1}$ in nitrogen
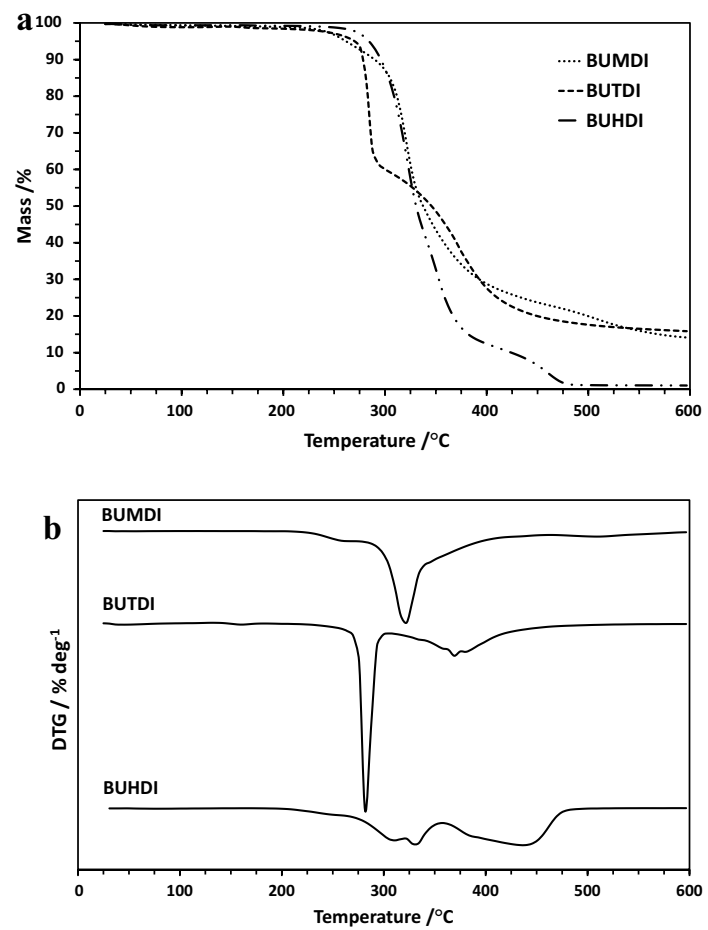
Fig. 12 TG (a) and DTG (b) curves of PUs based on BHPIQ recorded at heating rate $10{ }^{\circ} \mathrm{C} \mathrm{min}^{-1}$ in nitrogen

Table 6 Interpretation of TG and DTG curves of polyurethanes based on $\mathrm{BU}$ recorded at heating rate of $10{ }^{\circ} \mathrm{C} \mathrm{min}{ }^{-1}$ in nitrogen
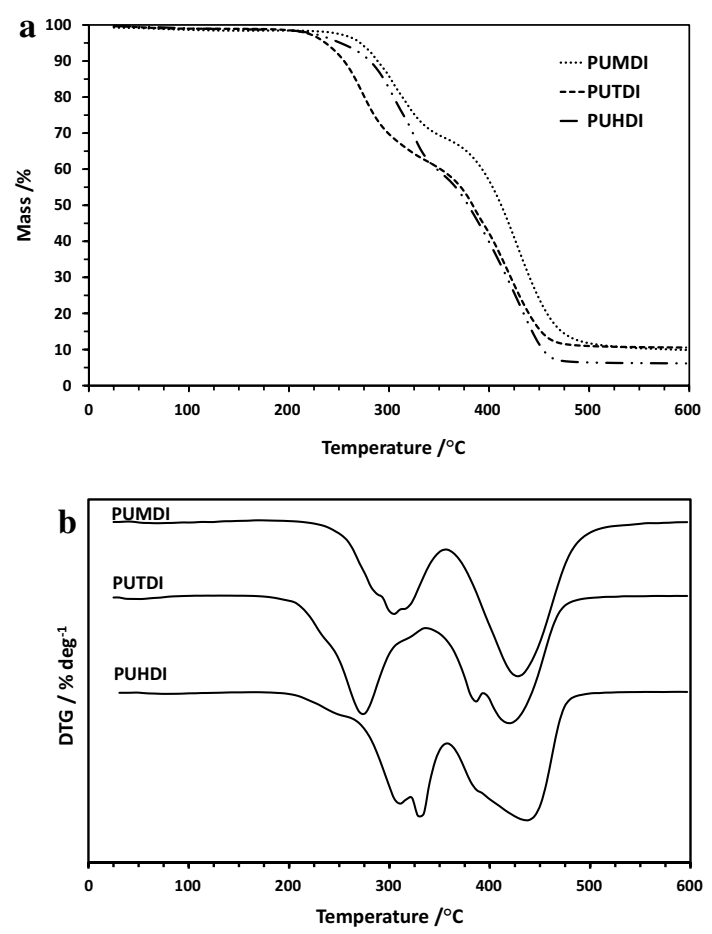

\begin{tabular}{llll}
\hline & BU-MDI & BU-TDI & BU-HDI \\
\hline$T_{5 \%}\left({ }^{\circ} \mathrm{C}\right)$ & 261 & 270 & 285 \\
$T_{10 \%}\left({ }^{\circ} \mathrm{C}\right)$ & 284 & 275 & 296 \\
$T_{20 \%}\left({ }^{\circ} \mathrm{C}\right)$ & 312 & 278 & 310 \\
$T_{50 \%}\left({ }^{\circ} \mathrm{C}\right)$ & 338 & 347 & 331 \\
Temp. range stage I & $200-450$ & $200-310$ & $220-345$ \\
$T_{\text {max } 1}\left({ }^{\circ} \mathrm{C}\right)$ & 321 & 283 & 323 \\
$\Delta m_{1}(\%)$ & 76.3 & 39.6 & 58.9 \\
Temp. range stage II & $450-600$ & $310-520$ & $345-410$ \\
$T_{\text {max } 2}\left({ }^{\circ} \mathrm{C}\right)$ & 510 & 372 & 352 \\
$\Delta m_{2}(\%)$ & 9.3 & 43.0 & 29.3 \\
Temp. range stage III & - & - & $410-520$ \\
$T_{\max 3}\left({ }^{\circ} \mathrm{C}\right)$ & - & - & 462 \\
$\Delta m_{3}(\%)$ & - & - & 10.8 \\
Remaining mass at $600{ }^{\circ} \mathrm{C}(\%)$ & 14.4 & 17.4 & 1.0 \\
\hline
\end{tabular}

\section{Thermogravimetric analysis of thermal decomposition characteristics of the PUs}

TG and DTG curves of the polyurethanes with and without imidazoquinazoline ring are presented in Figs. 11 and 12, respectively. The interpretation of the results for 
Table 7 Interpretation of TG and DTG curves of polyurethane samples based on BHPIQ recorded at heating rate of $10{ }^{\circ} \mathrm{C} \mathrm{min}{ }^{-1}$ in nitrogen

\begin{tabular}{llll}
\hline & PU-MDI & PU-TDI & PU-HDI \\
\hline$T_{5 \%}\left({ }^{\circ} \mathrm{C}\right)$ & 274 & 236 & 251 \\
$T_{10 \%}\left({ }^{\circ} \mathrm{C}\right)$ & 292 & 258 & 291 \\
$T_{20 \%}\left({ }^{\circ} \mathrm{C}\right)$ & 321 & 280 & 311 \\
$T_{50 \%}\left({ }^{\circ} \mathrm{C}\right)$ & 415 & 385 & 381 \\
Temp. range stage I & $180-365$ & $160-340$ & $180-315$ \\
$T_{\max 1}\left({ }^{\circ} \mathrm{C}\right)$ & 306 & 274 & 305 \\
$\Delta m_{1}(\%)$ & 30.8 & 37.4 & 25.4 \\
Temp. range stage II & $365-600$ & $340-395$ & $315-350$ \\
$T_{\max 2}\left({ }^{\circ} \mathrm{C}\right)$ & 431 & 387 & 326 \\
$\Delta m_{2}(\%)$ & 58.7 & 17.8 & 15.4 \\
Temp. range stage III & - & $395-550$ & $350-500$ \\
$T_{\max 3}\left({ }^{\circ} \mathrm{C}\right)$ & - & 421 & 433 \\
$\Delta m_{3}(\%)$ & - & 34.2 & 52.9 \\
Remaining mass at $600{ }^{\circ} \mathrm{C}(\%)$ & 10.5 & 10.6 & 6.3 \\
\hline
\end{tabular}

both samples is provided in Tables 6 and 7 .

Comparing the thermal stability of PUs obtained with the BHPIQ modifier, it was noted that the temperature of $5 \%$ of mass loss is the highest for PU-MDI $\left(T_{5 \%}=274{ }^{\circ} \mathrm{C}\right)$. This indicated the highest thermal stability of this sample. The remaining PUs with imidazoquinazoline ring, i.e., PU-HDI and PU-TDI, exhibited a lower temperature of $5 \%$ weight loss amounting to 251 and $236^{\circ} \mathrm{C}$, respectively.

It should be noted that the temperature of $20 \%$ weight loss is always higher in the case PUs with imidazoquinazoline rings than PUs based on 1,4-butanediol. It is connected with the imidazoquinazoline ring presence. The first stage of PUs degradation is connected with the urethane bond decomposition; therefore, the influence of imidazoquinazoline ring is not visible.

Decomposition of PU-MDI occurred in at least two stages, but the presence of the plateau at the initial stage of degradation could indicate a more complex mechanism. The first stage of degradation occurs in the temperature range of $180-365^{\circ} \mathrm{C}$ and was accompanied by $\Delta m_{1}=30.8 \%$ of mass loss. This stage was

Fig. 13 FTIR spectra of the evolved gaseous products from PU-MDI sample collected at $T_{\max }$

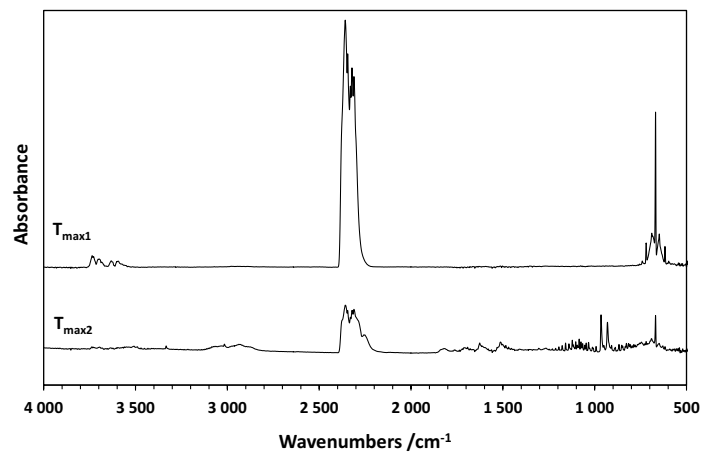


related to the cleavage of the weakest bond in the molecule, which was undoubtedly a urethane bond. It was accompanied by the emission of carbon dioxide, as evidenced by the presence of characteristic $\mathrm{CO}$ stretching bands in the range of $2300-2400 \mathrm{~cm}^{-1}$ and $689 \mathrm{~cm}^{-1}$ in the FTIR spectrum of evolved gases (Fig. 13).

In the second stage, which occurred at $365-600{ }^{\circ} \mathrm{C}$, the more thermally stable rings of imidazoquinazoline decomposed. This decomposition was accompanied by releasing of some additional gases such as: ammonia, which was evidenced by the presence of vibration bands at about 3333, 1626, 966 and $930 \mathrm{~cm}^{-1}$, methane-band at $3016 \mathrm{~cm}^{-1}$ or nitrogen oxides $\left(\mathrm{N}=\mathrm{O}\right.$ at $\left.1820 \mathrm{~cm}^{-1}\right)$. Aliphatic and aromatic compounds were also found as the decomposition products, as evidenced by the vibration in $-\mathrm{CH}_{3},>\mathrm{CH}_{2}$ groups in the range of $2750-3000 \mathrm{~cm}^{-1}$ and in the $\mathrm{C}=\mathrm{C}$ group at ca. $691 \mathrm{~cm}^{-1}$ as well as broadening of the band over $3000 \mathrm{~cm}^{-1}(\mathrm{C}=\mathrm{CH})$. Vibrations occurring at about $1513 \mathrm{~cm}^{-1}$ could originate from the $\mathrm{N}-\mathrm{H}$ bond in amines, while those at about $2252 \mathrm{~cm}^{-1}$ could be associated with the presence of $-\mathrm{NCO}$ groups in degradation products. The presence of residue at $600{ }^{\circ} \mathrm{C}$ was probably related to the formation of non-volatile complex structures composed of condensed aromatic rings.

The identification of degradation products of the obtained polyurethanes with imidazoquinazoline rings was carried out on the basis of NIST Mass Spectral Database [79]. The degradation products of polyurethanes were previously examined in the work [80] and the compound with the imidazoquinazoline ring in the work [81].

PU-TDI was characterized by the lowest thermal stability of all studied samples, as evidenced by the lowest $T_{5 \%}=236{ }^{\circ} \mathrm{C}$. This could be related to among others three times less molar mass of PU-TDI compared to the other samples. The decomposition of PU-TDI took place in three stages. The temperature of maximum mass loss rate at the first degradation step was $T_{\max 1}=274{ }^{\circ} \mathrm{C}$.

The presence of aliphatic (2800-3000 $\left.\mathrm{cm}^{-1}\right)$ and aromatic $\left(1636 \mathrm{~cm}^{-1}\right)$ derivatives was observed in addition to the carbon dioxide which derives from the decomposition of urethane bonds at the first stage of PU-TDI degradation occurring in the temperature range of $160-340{ }^{\circ} \mathrm{C}$. Above the $340{ }^{\circ} \mathrm{C}$, there was a split peak, indicating the complex mechanism of this stage. At the temperature of $T_{\max 2}=387^{\circ} \mathrm{C}$, FTIR spectra of evolved gases, ammonia (3333, 965 and

Fig. 14 FTIR spectra of the evolved gaseous products from PU-TDI sample collected at $T_{\max }$

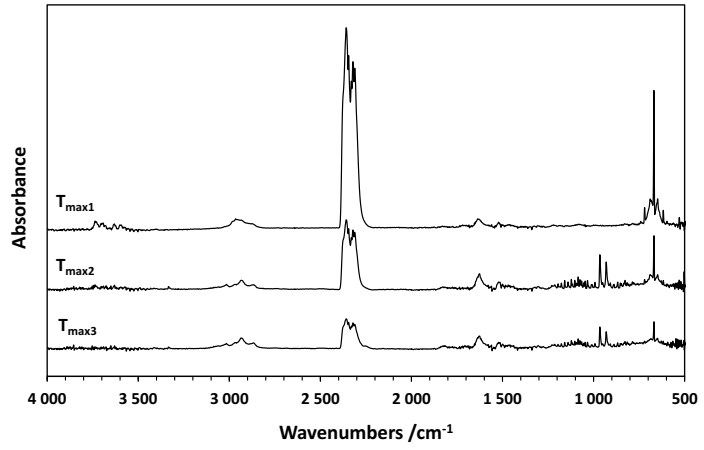


Fig. 15 FTIR spectra of the evolved gaseous products from PU-HDI sample collected at $T_{\max }$

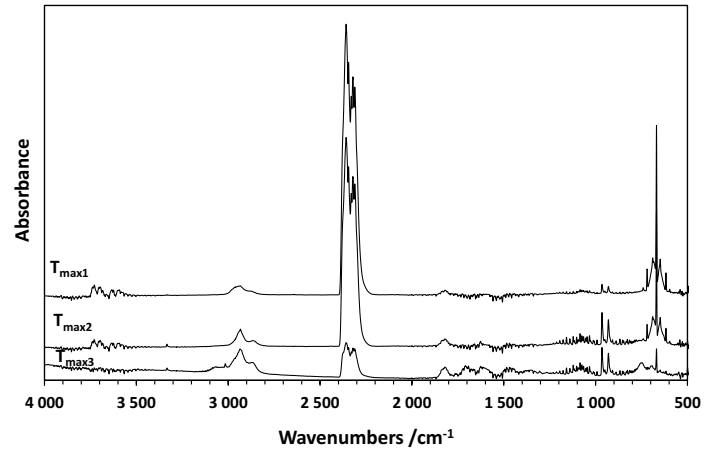

$\left.930 \mathrm{~cm}^{-1}\right)$ and probably methane $\left(3016 \mathrm{~cm}^{-1}\right)$, were found. The intensity of the identified bands was reduced in the third step at $T_{\max 3}=421{ }^{\circ} \mathrm{C}$ (Fig. 14).

The decomposition of the aliphatic polyurethane with the imidazoquinazoline ring-PU-HDI took place in at least three stages, as evidenced by the presence of three peaks on the DTG curve. The first stage of degradation occurred in the range of $180-315^{\circ} \mathrm{C}$ and was accompanied by $25.4 \%$ of mass loss. The second stage was observed in the range of $315-350{ }^{\circ} \mathrm{C}$ with a mass loss of $15.4 \%$.

In the first stage apart from the releasing carbon dioxide (stretching vibrations in the range of $2300-2400 \mathrm{~cm}^{-1}$ and $689 \mathrm{~cm}^{-1}$ ), ammonia was additionally observed, as evidenced by vibrations at ca. 965 and $930 \mathrm{~cm}^{-1}$. There were also aliphatic structures which were confirmed by vibration of $-\mathrm{CH}_{3}, \mathrm{CH}_{2}$ groups in the range of $2900-3000 \mathrm{~cm}^{-1}$. Additionally, a band at about $1820 \mathrm{~cm}^{-1}$ was found, which may be associated with the presence of nitrogen oxides (Fig. 15a).

In the second stage at $T_{\max 3}=326{ }^{\circ} \mathrm{C}$, an increase in the intensity of the bands was observed, which were identified in the first stage (Fig. 15b), which could indicate a similar mechanism of both stages.

The third stage of degradation was in the range of $350-500{ }^{\circ} \mathrm{C}$ and was related to the decomposition of the diol modifier. The temperature of maximum mass loss rate at this stage was $433{ }^{\circ} \mathrm{C}$, and the mass loss was $\Delta m_{3}=52.9 \%$. The presence of the plateau at the initial stage of decomposition could indicate the complex mechanism of this stage. In this step (Fig. 15c), the presence of carbonyl group vibrations at about $1700 \mathrm{~cm}^{-1}$ and the vibration of the $\mathrm{C}=\mathrm{C}$ group at ca. $1620 \mathrm{~cm}^{-1}$ was additionally found. Broadening of the band in the range of $3000-3200 \mathrm{~cm}^{-1}$ and the presence of vibration at approx. $747 \mathrm{~cm}^{-1}$ could indicate the presence of aromatic rings in degradation products. In addition, the band at $3016 \mathrm{~cm}^{-1}$ could indicate the presence of methane. The residue at $600{ }^{\circ} \mathrm{C}$ of $6.3 \%$ was the smallest of all the studied samples.

Samples of unmodified PUs were generally characterized by a two-stage thermal decomposition in the range of $200-600{ }^{\circ} \mathrm{C}$. The highest temperature of $5 \%$ of the mass loss of $285^{\circ} \mathrm{C}$ shown, as expected [82], a sample synthesized from an aliphatic HDI. However, this sample was characterized by the lowest amount of char. This could be due to the specific aliphatic structure of the PU chain. There were not any aromatic moieties which could more easily condense. 
A 5\% weight loss of the remaining BU-MDI and BU-TDI took place at 261 and $270{ }^{\circ} \mathrm{C}$, respectively. It indicated that only the modified PU obtained with MDI show higher thermal stability than unmodified ones (see Tables 6 and 7). In the other cases, we observed the opposite phenomenon. This was due to the fact that at the beginning of degradation less thermally stable urethane groups decomposed, and latter imidazoquinazoline ring degraded. Ultimately, the effect of the presence of imidazoquinazoline rings in the polymer structure on the increase of its thermal stability could be noted. It should be emphasized that imidazoquinazoline ring-modified PUs exhibited lower mass losses in the first decomposition stage than non-modified PUs. The temperature ranges of the first stage of decomposition of modified and unmodified PUs differed slightly from each other, which made the comparison difficult. However, it was possible to compare the mass loss of all PUs at e.g. $350{ }^{\circ} \mathrm{C}$. They amount to: BU-HDI 58.9\%; PU-HDI 40.8\%; BUMDI 56.2\%; PU-MDI 30.8\%; BU-TDI 52.4\% PU-TDI $37.4 \%$.

\section{Conclusions}

Linear polyurethanes with imidazoquinazoline rings were obtained with the use of diol -1-phenyl-2,6-bis(2-hydroxyimidazo[1,5-c]quinazoline-3,5-dione. The synthesis conditions of these polyurethanes with selected aliphatic and aromatic diisocyanates have been developed. It was found that the reaction with hexamethylene 1,6-diisocyanate was the fastest, while the aromatic isocyanates reacted more slowly, in the order of 4,4'-diphenylmethane diisocyanate and toluene 2,4-diisocyanate. This was conditioned by the spatial course of the reactions.

The composition (elemental analysis) and structure $\left({ }^{1} \mathrm{H}-\mathrm{NMR}\right.$ and IR spectra) of the resulting linear polyurethanes with imidazoquinazoline rings were confirmed by instrumental methods. The determined molar masses indicate that the use of hexamethylene 1,6-diisocyanate and diphenylmethane 4,4'-diisocyanate resulted in the polymers formation. In turn, the product obtained by reaction of diol with toluene 2,4-diisocyanate was an oligourethane.

All obtained modified polyurethanes were amorphous. It was connected with the asymmetrical structure of BHPIQ.

The presence of imidazoquinazoline rings in polyurethane chains has a stabilizing effect. It makes the polymer is more stable at elevated temperatures, its initial degradation rate is reduced and the amount of released degradation products is also reduced.

Introduction of the imidazoquinazoline ring into the chain of the polyurethanes increases their glass transition temperature, which increases the heat resistance of the polymer. Thus, the modified polyurethanes retain their better properties at higher temperatures.

It should be emphasized that the glass transition temperature of the resulting modified polyurethane based on MDI exceeds $150{ }^{\circ} \mathrm{C}$, which is characteristic of only a few plastics. 
These new polyurethanes can be used as additives to modify the thermal and or mechanical properties of other polymers, polymer composites with in hybrid nanocomposites. The last ones will be the subject of next paper.

Acknowledgements NMR spectra were made in the Laboratory of Spectrometry, Faculty of Chemistry, Rzeszow University of Technology, and was financed from DS budget.

Open Access This article is distributed under the terms of the Creative Commons Attribution 4.0 International License (http://creativecommons.org/licenses/by/4.0/), which permits unrestricted use, distribution, and reproduction in any medium, provided you give appropriate credit to the original author(s) and the source, provide a link to the Creative Commons license, and indicate if changes were made.

\section{Reference}

1. Howarth G (2003) Polyurethanes, polyurethane dispersions and polyureas: past, present and future. Surf Coat Int Part B Coat Trans 86:111-118

2. Król P (2009) Poliuretany-przegląd 60-letniego rozwoju ich syntezy i zastosowań. Polimery 54:439-500

3. Przybylski J (2008) Asocjacyjne poliuretanowe modyfikatory właściwości reologicznych wodnych dyspersji polimerów. Polimery 53:440-445

4. Król P (2007) Synthesis methods, chemical structures and phase structures of linear polyurethanes. properties and applications of linear polyurethanes in polyurethane elastomers, copolymers and ionomers. Prog Mat Sci 52:915-1015

5. Resiak I, Rokicki G (2000) Modified polyurethanes for biomedical applications. Polimery 45:592-602

6. Brzeska J, Dacko P, Janeczek H, Kowalczuk M, Janik H, Rutkowska M (2010) Wpływ syntetycznego polihydroksymaślanu na wybrane właściwości nowych, otrzymanych z jego udziałem, poliuretanów do zastosowań medycznych Cz II Poliuretany z cykloalifatycznym diizocyjanianem w segmencie sztywnym, Poliuretany $\mathrm{z}$ aromatycznym diizocyjanianem w segmencie sztywnym. Polimery $55: 41-46$

7. Zhou X, Zhang T, Jiang X, Gu N (2010) The surface modification of medical polyurethane to improve the hydrophilicity and lubricity: the effect of pretreatment. J Appl Polym Sci 116:1284-1290

8. Chantsoulis M, Świątkowska-Wróblewska K, Skrzek A, Urbanowska J, Chamela-Bilińska D, Zwoliński J, Sakowski J (2009) Wykorzystanie biowchłanialnych implantów w leczeniu operacyjnym choroby zwyrodnieniowej kręgosłupa szyjnego. Phys Med 15:66-69

9. Russo L, Russo T, Battocchio C, Taraballi F, Gloria A, D'Amora U, De Santis R, Polzonetti G, Nicotra F, Ambrosio L, Cipolla L (2015) Galactose grafting on poly( $\varepsilon$-caprolactone) substrates for tissue engineering: a preliminary study. Carbohydr Res 405:39-46

10. Jayabalan M, Lizymol P, Thomas V (2000) Synthesis of hydrolytically stable low elastic modulus polyurethane-urea for biomedical applications. Polym Int 49:88-92

11. Bayer O (1947) Das di-isocyanat-polyadditionsverfahren (polyurethane). Angew Chem 59:257-272

12. Dmitrienko S, Zolotov Y (2002) Polyurethane foams in chemical analysis: sorption of various substances and its analytical applications. Russ Chem Rev 71:159-168

13. Kosyanchuk L, Lipatov Y, Babich V, Perepelitsyna L (2003) Effect of filler on the relaxation time spectra of filled polymers. Polym Sci Ser A 45:644-650

14. Grishchuk S, Alekseeva T, Lipatov Y (2003) Kinetics of formation of interpenetrating polymer networks based on poly(urethane) and polystyrene. Polym Sci Ser A 45:366-380

15. Lebedev B, Kulagina T, Smirnova N, Markin A, Meijer A, Versteegen R (2004) Thermodynamics of linear poly(pentamethylene urethane) and poly(hexamethylene urethane) in the range from 0 to 450 K. Macromol Chem Phys 205:230-238

16. Fernandez C, Bermudez M, Versteegen R, Meijer E, Muller A, Munoz-Guerra S (2009) Crystallization studies on linear aliphatic $n$-polyurethanes. J Polym Sci Part B Polym Phys 47:1368-1377 
17. Fernandez C, Bermudez M, Munoz-Guerra S, Leon S, Versteegen R, Meijer E (2010) Crystal structure and morphology of linear aliphatic n-polyurethanes. Macromolecules 43:4161-4171

18. Rutkowska M (1981) Polyurethane grafted onto styrene-styrene sulfonic acid. Polimery 26:360-368

19. Kościelecka A, Dzierza W (1987) Termiczna degradacja poliuretanów. Polimery 32:58-67

20. Król P (2007) Synthesis methods, chemical structures and phase structures of linear polyurethanes. Elastomers, copolymers and ionomers. Prog Mat Sci 52:915-1015

21. Sidouni F, Nurdin F, Nurdin F, Chabrecek P (2001) Surface properties of a specifically modified high-grade medical polyurethane. Surf Sci 491:355-369

22. Ravey M, Pearce E (1997) Flexible polyurethane foam. I. Thermal decomposition of a polyetherbased, water-blown commercial type of flexible polyurethane foam. J Appl Polym Sci 63:47-74

23. Levchik S, Weil E (2004) Thermal decomposition, combustion and fire-retardancy of polyurethanes: a review of the recent literature. Polym Int 53:1585-1610

24. Woo HY, Shim H-K, Lee K-S (1998) Synthesis and optical properties of polyurethanes containing a highly NLO active chromophore. Macromol Chem Phys 199:1427-1433

25. Lee J-Y, Bang H-B, Kang T-S, Park E-J (2004) Molecular design, synthesis and electro-optic properties of novel Y-type polyurethanes with high thermal stability of second harmonic generation. Eur Polym J 40:1815-1822

26. Pan Y, Tang X, Zhu L, Huang Y (2007) Synthesis and characterization of a new high-Tg photorefractive material. Eur Polym J 43:1091-1095

27. Oprea S, Gradinariu P, Joga A, Oprea V (2013) Synthesis, structure and fungal resistance of sulfadiazine-based polyurethane ureas. Polym Degrad Stab 98:1481-1488

28. Chen SJ, Hu JL, Yuen CW, Chan LK (2009) Supramolecular polyurethane networks containing pyridine moieties for shape memory materials. Mater Lett 63:1462-1484

29. Tsou C-H, Lee H-T, Tsai H-A, Cheng H-J, Suen M-C (2013) Synthesis and properties of biodegradable polycaprolactone/polyurethanes by using 2,6-pyridinedimethanol as a chain extender. Polym Degrad Stab 98:643-650

30. Oprea S, Potolinca VO, Varganici C-D (2016) Synthesis and properties of polyurethane urea with pyridine-2,6-dicarboxamide moieties in their structure. RSC Adv 6:106904-106913

31. Mahapatra SS, Rana S, Cho JW (2011) Synthesis of s-triazine-based hyperbranched polyurethane for novel carbon-nanotube-dispersed nanocomposites. J Appl Polym Sci 120:474-483

32. Rao BN, Yadav PJP, Malkappa K, Jana T, Sastry PU (2015) Triazine functionalized hydroxyl terminated polybutadiene polyurethane: influence of triazine structure. Polymer 77:323-333

33. Oprea SJ (2012) Novel quinoline-based polyurethane elastomers. The effect of the hard segment structure in properties enhancement. J Polym Res 19:9767-9775

34. Galimberti M, Barbera V, Citterio VA, Sebastiano R, Truscello A, Valerio AM, Conzatti L, Mendichi R (2015) Supramolecular interactions of carbon nanotubes with biosourced polyurethanes from 2-(2,5-dimethyl-1H-pyrrol-1-yl)-1,3-propanediol. Polymer 63:62-70

35. Oprea S (2013) Effect of pyridazine content and crosslinker structure on the properties of polyurethane elastomers. J Appl Polym Sci 128:3974-3981

36. Gorna K, Gogolewski S (2006) Biodegradable porous polyurethane scaffolds for tissue repair and regeneration. J Biomed Mater Res A 79A:128-138

37. Javni I, Bilic O, Bilic N, Petrovic ZS, Eastwood EA, Zhang F, Ilavsk J (2015) Thermoplastic polyurethanes with isosorbide chain extender. J Appl Polym Sci 132:42830-42839

38. Marin R, Munoz-Guerra S (2009) Carbohydrate-based poly(ester-urethane)s: a comparative study regarding cyclic alditols extenders and polymerization procedures. J Appl Polym Sci 114:3723-3736

39. Oprea S, Potolinca VO, Oprea V (2016) Synthesis and properties of new crosslinked polyurethane elastomers based on isosorbide. Eur Polym J 83:161-172

40. Kramarenko VY, Ezquerraz TA, Balta-Calleja FJ, Privalko VP (2000) The effects of different positions of the pyridine functional groups on the-dielectrical relaxation of polyureas-polyurethanes elastomers. J Mater Sci 35:5021-5028

41. Kramarenko VY, Privalko VP (2004) Structure-property relationships for model heterocyclic polymer networks: effect of network density. Polym Sci Ser A 46:143-150

42. Turac E, Sahmetlioglu E, Toppare L, Yuruk H (2011) Synthesis and characterization of conducting copolymers of quinoxaline derivatives. J Appl Polym Sci 120:1713-1719

43. Pardo MA, Perez JM, del Valle MA, Godoy MA, Diaz FR (2014) Pyridine based polymers: synthesis and characterization. J Chil Chem Soc 59:2464-2467 
44. Anderson EB, Long TE (2010) Imidazole and imidazolium-containing polymers for biology and material science applications. Polymer 51:2447-2454

45. Oprea S, Potolinca VO (2012) Synthesis and characterization of photoactive polyurethane elastomers with 2,3-dihydroxypyridine in the main chain. J Mater Sci 47:677-684

46. Potolinca VO, Buruiana E, Oprea S (2013) Dielectric behavior of polyurethane and polyurethane-urea elastomers with pyridine moieties in the main chain. J Polym Res 20:237-242

47. Weng N-Ch, Wu Ch-F, Tsen W-Ch, Wu Ch-L, Suen M-Ch (2018) Synthesis and properties of shape memory polyurethanes generated from schiff-base chain extender containing benzoyl and pyridyl rings. Des Monomers Polym 21:55-63

48. Wan L, Luo Y, Xue L, Tian J, Hu Y, Qi H, Shen X, Huang F, Lei D, Chen X (2007) Preparation and properties of a novel polytriazole resin. J Appl Polym Sci 104:1038-1042

49. Rana S, Lee SY, Cho JW (2010) Synthesis and characterization of biocompatible poly(ethylene glycol)-functionalized polyurethane using click chemistry. Polym Bull 64:401-411

50. Priyanka KG, Mishra AK, Kantheti S, Narayan R, Raju KVSN (2012) Synthesis of triazole ringcontaining pentol chain extender and its effect on the properties of hyperbranched polyurethane-urea coatings. J Appl Polym Sci 126:2024-2034

51. Gite VV, Mahulikar PP, Hundiwale DG (2010) Preparation and properties of polyurethane coatings based on acrylic polyols and trimer of isophorone diisocyanate. Prog Org Coat 68:307-312

52. Camberlin Y, Pascault JP (1983) Quantitative DSC evaluation of phase segregation rate in linear segmented polyurethanes and polyurethaneureas. J Polym Sci Polym Chem 21:415-423

53. Tonelli C, Trombetta T, Scicchitano M, Simeone G, Ajroldi G (1996) New fluorinated thermoplastic elastomers. J Appl Polym Sci 59:311-327

54. Tonelli C, Trombetta T, Maccone P (2000) Synthesis and physical characterization of model hard segments based on diphenyl methane diisocyanate and hydroquinone bis(2-hydroxyethyl) ether. J Polym Sci Polym Chem 37:1437-1487

55. Padmavathy T, Srinivasan KSV (2003) Liquid crystalline polyurethanes: a review. J Macromol Sci Polym R C43:45-85

56. Saito Y, Nansai S, Kinoshita S (1972) Structural studies on polyurethane fibers. I. Crystal and molecular structures of aliphatic polyurethanes from hexamethylene diisocyanate and some linear glycols. Polym J 3:113-120

57. Blackwell J, Gardner K (1979) Structure of the hard segments in polyurethanes elastomers. Polymer 20:13-17

58. Saito Y, Hara K, Kinoshita S (1982) Structural studies on linear polyurethanes. II. Crystal and molecular structures of aliphatic polyurethanes from trimethylene diisocyanate, and tetra- and hexamethylene glycols. Polym J 14:19-31

59. Neffgen S, Kusan J, Fey T, Keul H, Hocker H (2000) Synthesis and thermal properties of [n]-polyurethanes. Macromol Chem Phys 201:2108-2115

60. Kultys A, Pikus S (2001) Polyurethanes containing sulfur. III. New thermoplastic HDI-based segmented polyurethanes with diphenylmethane unit in their structure. J Polym Sci A Polym Chem 39:1733-1742

61. Kultys A, Podkościelny W, Pikus S (1999) Polyesters containing sulfur. VI. Synthesis and characterization of polyesters from naphthalene-1,4- or naphthalene-1,5-bis(methylthioacetic acid) and aliphatic diols. J Polym Sci A Polym Chem 37:4140-4150

62. Murakami H, Baba R, Fukushima M, Nonaka N (2015) Synthesis and characterization of polyurethanes crosslinked by polyrotaxanes consisting of half-methylated cyclodextrins and PEGs with different chain lengths. Polymer 56:368-374

63. Klasek A, Koristek K, Lycka A, Holcapek M (2003) Unprecedented reactivity of 3-amino-1H,3Hquinoline-2,4-diones with urea: an efficient synthesis of 2,6-dihydro-imidazo[1,5-c]quinazoline3,5-diones. Tetrahedron 59:1283-1288

64. PN-EN 1242:2006.

65. Wunderlich B (2005) Thermal analysis of polymeric materials. Springer, Berlin

66. Pyda M (2014) Temperature-modulated differential scanning calorimetry (TMDSC). In: Encyclopedia of polymer science and technology. Wiley, Hoboken, pp 1-30

67. Bailey ME, Kirss V, Spaunburgh RG (1956) Reactivity of Organic Is, cyanates. Ind Eng Chem 48:794-797

68. Richter RH (2000) Priester RD (2000) Isocyanates, organic, in kirk-othmer encyclopedia of chemical technology. Wiley, New York 14:902-934 
69. Painter PC, Coleman MM (1997) Fundamentals of polymer science: an introductory text. Technomic Pub Co, Oxford, p 1

70. McCrum NG, Buckley CP, Bucknall CB (1997) Principles of polymer engineering. Oxford University Press, New York, $\mathrm{p} 1$

71. Jensen WB (2008) The origin of the polymer concept. J Chem Edu 88:624-625

72. Allcock HR, Lampe FW, Mark JE (2003) Contemporary Polymer Chemistry, 3rd edn. Pearson Education, New York, p 21

73. Zhang J, Tua W, Dai Z (2012) Synthesis and characterization of transparent and high impact resistance polyurethane coatings based on polyester polyols and isocyanate trimmers. Prog Org Coat 75:579-583

74. Rogulska M, Podkościelny W, Kultys A, Pikus S, Poździk E (2006) Studies on thermoplastic polyurethanes based on new diphenylethane-derivative diols. I. Synthesis and characterization of nonsegmented polyurethanes from HDI and MDI. Europ Polym J 42:1786-1797

75. Yilgor I, Yilgor E, Wilkes GL (2015) Critical parameters in designing segmented polyurethanes and their effect on morphology and properties: a comprehensive review. Polymer 58:A1-A36

76. Pyda M, Van Durme K, Wunderlich B, Van Mele B (2005) Heat capacity of poly(vinyl methyl ether). J Polym Sci Part B Polymer Physics 43:2141-2153

77. Czerniecka-Kubicka A, Schliesser J, Popovic M, Woodfield BF, Walczak M, Zarzyka I, Pyda M (2017) Molecular interpretation of low-temperature heat capacity of aliphatic oligo-urethane. Chem Thermodyn 112:299-307

78. Czerniecka-Kubicka A, Schliesser J, Woodfield BF, Zarzyka I, Pyda M (2015) Vibrational Heat Capacity of Poly(N-isopropylacrylamide). Polymer 63:108-115

79. http://webbook.nist.gov/chemistry/]

80. Byczyński Ł, Dutkiewicz M, Januszewski R (2017) The effect of epoxyurethane modification on surface and thermal properties of fluorinated epoxyfunctional siloxane high: solid coatings. Prog Org Coat 108:51-58

81. Szyszkowska A, Trzybiński D, Pawlędzio S, Woźniak K, Klasek A, Zarzyka I (2018) Thermal stability and flame retardancy of polyurethanes. J Mol Struct 1153:230-238

82. Chattopadhyay DK, Webster DC (2009) Thermal stability and flame retardancy of polyurethanes. Prog Polym Sci 34:1068-1133

Publisher's Note Springer Nature remains neutral with regard to jurisdictional claims in published maps and institutional affiliations. 